\title{
COCO-POWER: EXPLORING COPRA- DERIVED BIODIESEL FOR GRID CONNECTED ELECTRICITY IN VANUATU
}

A Thesis Submitted to Victoria University of Wellington in Fulfilment of the Requirements for the Degree of Master of Science in Geography

\author{
Author: \\ Primary Supervisor: \\ Timothy George Hewitt \\ Dr. Sean Weaver \\ MSc Candidate \\ Senior Lecturer
}

School of Geography, Environment and Earth Sciences

Te Kura Tātai Aro Whenua

Victoria University of Wellington 
Many people have helped this research by openly giving information, guidance and support.

The people that I interviewed in Vanuatu - Alick Berry, Claire Dornic, David Stein, Francois Py, Gabriel Bani, John Chaniel, Jone Roqara, Leo Moli, Olivier Roupsard, Peter Nepwatt, Queni Signo, Stanley Temakon, Thomas Bangalini, Tony Deamer, and Yann Do Quang - made the research project possible by openly discussing the opportunities and issues in Vanuatu. This was furthered by the official endorsement of the Vanuatu Carbon Credits Project by the Vanuatu Council of Ministers as well as the growing relationship between the Vanuatu National Advisory Committee on Climate Change and the Vanuatu Carbon Credits Project International team. Russel Nari and Brian Phillips of the Vanuatu National Advisory Committee on Climate Change were particularly helpful and supportive.

My primary supervisor, Dr. Sean Weaver, has been instrumental in my research. He initiated my connection with the topic via the Vanuatu Carbon Credits Project, which he established. Sean has accepted me not as a student, but a fellow researcher, which has encouraged my enthusiasm and professionalism. Sean has given me an abundant amount of time to help guide me through the academic process as well as adding structure to my often cluttered thoughts.

In the new and fast changing topic of the clean development mechanism I have often found literature out of date, but have been very fortunate to have received advice from a number of experts including Dr. Sean Weaver, Murray Ward, Dr. Ralph Sims, Pala Molisa, Dr. Stephen Keef and Robert O’Sullivan.

The School of Geography, Environment and Earth Sciences at Victoria University of Wellington has given me academic freedom to explore the world from my perspective of action research and applied geography. The University has access to a great and growing number of academic databases and journals, which are an imperative to completing further relevant academic research. Also, Victoria University of Wellington granted me permission to represent the University as an accredited observer at the COP-13 
International Climate Change Conference in Bali in 2007, which gave me a greatly improved insight into the research topic.

Finally, I would like to thank my family and my partner Abby Smith who showed extraordinary levels of patience in their ongoing support of my research. They have also been kind but critical sounding boards for ideas and proof readers of a topic that was formerly foreign to them. They may now say that they are well read on the topic of biodiesel production in Vanuatu!

Tim Hewitt,

Wellington, April 2008 
AAU Assigned Amount Unit

ADB Asian Development Bank

AM0047 Approved Methodology number 47 (of the CDM)

AMS-I.D. Approved small scale methodology for project activities in the category I.D. (of the CDM)

APCC Asian and Pacific Coconut Community

AusAID Australian Agency for International Aid

Bbl Barrel

BM Building Margin

CAPM Capital Asset Pricing Model

CDM Clean Development Mechanism

CEO Chief Executive Officer

CER Certified Emission Reduction

CIRAD Centre de coopération internationale en recherche agronomique pour le développement

CLA-CC Claire's Luganville Agencies - Copra Crushing

CM Combined Margin

CMP Conference of the parties (to the UNFCCC) serving as the meeting of the parties to the Kyoto Protocol

$\mathrm{CO}_{2} \quad$ Carbon dioxide

$\mathrm{CO}_{2}$-e Carbon dioxide equivalent (i.e. amount of $\mathrm{CO}_{2}$ that is equivalent to the greenhouse gases being referred to, in terms of global warming potential)

COP Conference Of Parties (to the UNFCCC)

CP1 Commitment Period One (i.e. 2008-2012 in reference to the Kyoto Protocol)

CP2 Commitment Period Two (i.e. Kyoto Protocol period after 2012, which is currently undefined)

CSR Corporate Social Responsibility

DNA Designated National Authority (under the CDM)

DOE Designated Operational Entity

EB Executive Board (of the CDM)

EC European Commission

EDF European Development Fund

EF Emission factor 


\begin{tabular}{ll} 
EIB & European Investment Bank \\
ERU & Emission Reduction Unit (from JI projects) \\
ETS & Emission Trading Scheme \\
EU & European Union \\
G8 & Group of Eight \\
GDP & Gross Domestic Product \\
GEEREF & Global Energy Efficiency and Renewable Energy Fund \\
GOF & Global Opportunities Fund \\
GoV & Government of Vanuatu \\
IEA & International Energy Agency \\
IMF & International Monetary Fund \\
IPCC & Intergovernmental Panel on Climate Change \\
IRR & Internal Rate of Revenue \\
JI & Joint Implementation mechanism of the Kyoto Protocol \\
Kg & Kilogram(s) \\
KSPX & Kontiki South Pacific Stock Exchange Index \\
KW & Kilowatt \\
MBtu & Million British Thermal Units \\
MDG & Millennium Development Goal \\
MOP & Meeting Of Parties \\
MSc & Master of Science degree \\
MW & Megawatt \\
MWh & Megawatt hour \\
NACCC & National Advisory Committee on Climate Change \\
NGO & Non-Government Organisation \\
NPV & Net Present Value \\
NZAID & New Zealand Agency for International Development \\
ODA & Official Development Assistance \\
OM & Operating Margin \\
PDD & Project Design Document \\
PIN & Project Idea Note \\
PIC & Pacific Island Country \\
REDD & Reducing Emissions from Deforestation and \\
& Degradation \\
\hline
\end{tabular}


REEEP Renewable Energy and Energy Efficiency Partnership

SIDS Small Island Developing States

SOPAC South Pacific Applied Geoscience Commission

SPREP Secretariat of the Pacific Regional Environment Programme

SVO Straight Vegetable Oil

UN United Nations

UNELCO Union Electrique Coloniale

UNFCCC United Nations Framework Convention on Climate Change

USA United States of America

USAID United States Agency for International Development

USD United States Dollar currency

VCCP Vanuatu Carbon Credits Project

VANREPA Vanuatu Renewable Energy and Power Association

VAST Vanuatu Air Sea Transit

VAT Value Added Tax

VCMB Vanuatu Commodities Marketing Board

VCPL Vanuatu Copra Processing Limited

VER Verified Emission Reduction

VUW Victoria University of Wellington

WACC Weighted Average Cost of Capital 
This research assesses the financial feasibility of a large scale copra-based biodiesel refinery in Vanuatu and whether any carbon finance could be sought to improve the viability of the project. The research cannot be perfectly predictive of the next fifteen years of financial situation, however, the research can quite accurately replicate the feasibility assessment that potential investors would make. The research finds that the project is not financially viable under current projections without carbon finance. The research also shows that carbon finance could be sought from a number of sources in order to make the project feasible. Under current projections the research finds that utilising the clean development mechanism would add approximately 2.9 million United States Dollars (USD) to the present value of the project. The conclusion from these results is that the proposed biodiesel project is sufficiently profitable to attract investors. The primary recommendation resulting from the research is that the stakeholders to the proposed biodiesel project begin an open discourse to work through any issues in order to develop a sustainable copra-based biodiesel refinery in Vanuatu to produce a substitute for the import of fossil diesel used for electricity generation in Port Vila. The secondary recommendation is that international climate change policy negotiators should keep in mind the full set of barriers when addressing the uptake of clean technology in developing countries; often it may not only be the financial feasibility that is preventing climate change mitigation activities.

Key words: biodiesel, Clean Development Mechanism (CDM), carbon finance, electricity, feasibility, Vanuatu. 


\section{CONTENTS}

Acknowledgements ii

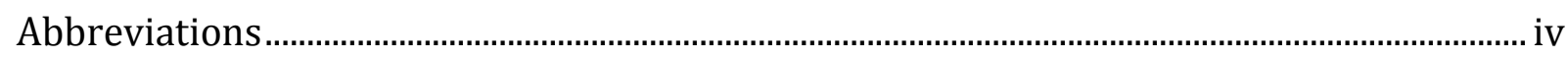

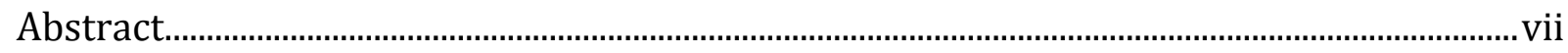

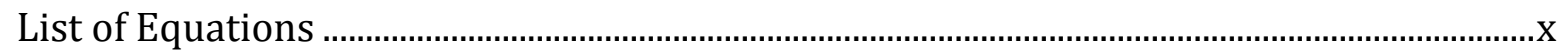

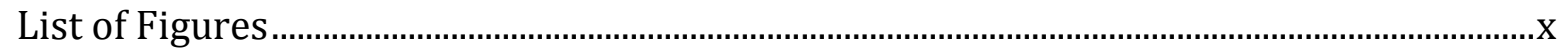

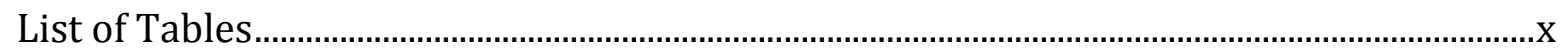

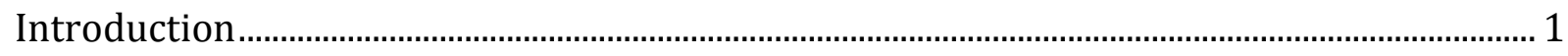

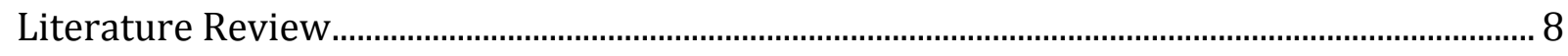

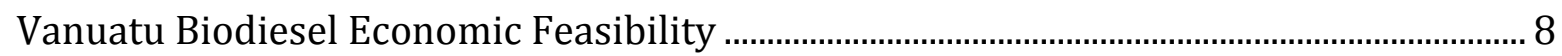

Carbon Finance Opportunities...................................................................................................11

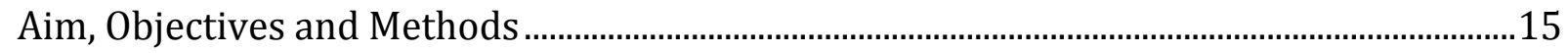

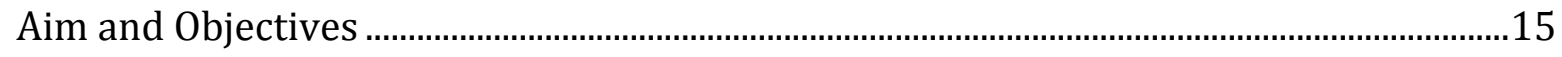

Overarching Methodology .......................................................................................................

Economic Feasibility Methodology .....................................................................................18

Carbon Finance Opportunities Methodology ……………......................................................19

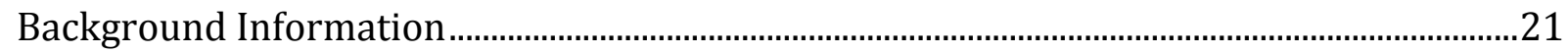

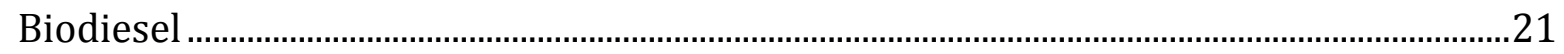

Kyoto Protocol and the Clean Development Mechanism ........................................................26

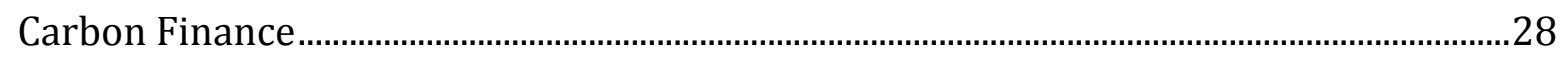

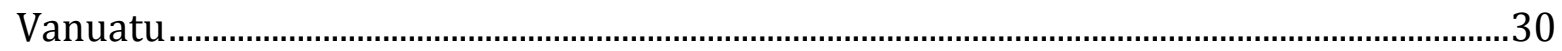

Vanuatu Carbon Credits Project....................................................................................................32

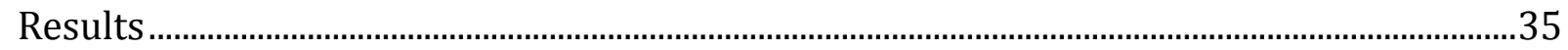

Biodiesel Economic Feasibility ...................................................................................................

Carbon Finance Opportunities......................................................................................................52

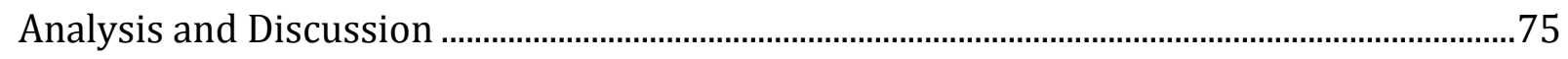




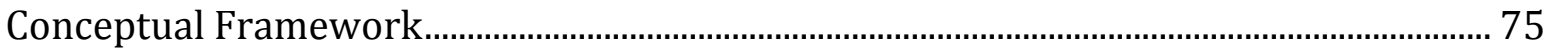

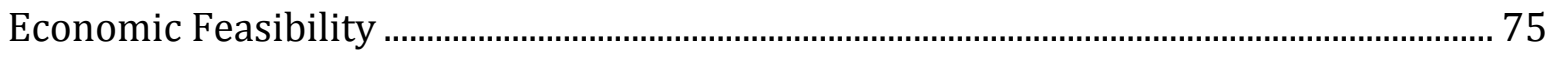

Political Role in Economic Feasibility .................................................................................... 76

Carbon Finance Analysis ................................................................................................................... 78

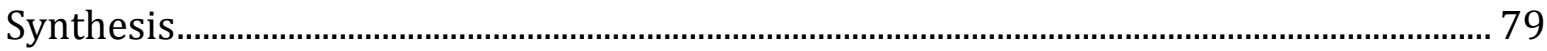

Conclusions/Recommendations .............................................................................................. 80

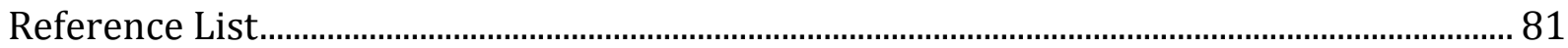

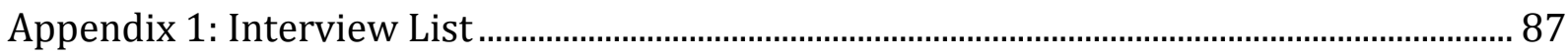

Appendix 2: Ethics Approval ......................................................................................................... 88

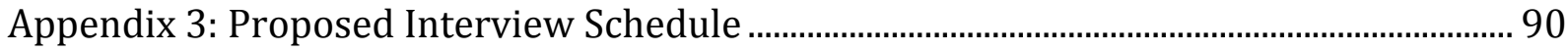

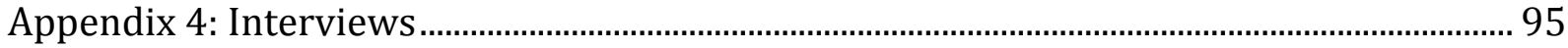




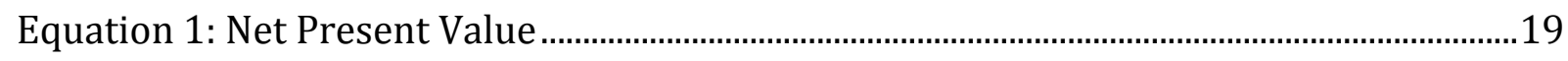

Equation 2: Typical Biodiesel Reaction ...........................................................................................22

Equation 3: Annual Rate of Price Change.......................................................................................39

Equation 4: Hamada's Formula: Adapted from Hamada (1972)...............................................41

Equation 5: Hamada's Formula - Substitution of Allegro Biodiesel Corporation Data ......41

Equation 6: Capital Asset Pricing Model ...........................................................................................42

Equation 7: Capital Assest Pricing Model - Substitution of Data ...............................................42

Equation 8: Mean Annual Rate of Change .......................................................................................43

Equation 9: Operating Margin Calculation ..................................................................................63

Equation 10: Baseline Methodology Calculation ……………………………………………..65

Equation 11: Emissions from Methanol (From AM0047) …………………………………....68

\section{LIST OF FIGURES}

Figure 1: Biodiesel Plant in Kakinada, India...........................................................................22

Figure 2: Map of Vanuatu (Source: MapQuest 2006) …………………………………………..30

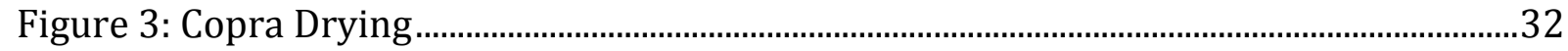

Figure 4: Vanuatu Carbon Credits Project Representation at UNFCCC COP13/MOP3 .......34

Figure 5: Diesel Generator at Tagabe power Plant......................................................................61

Figure 6: Copra Drying on the Island of Santo, Vanuatu ..............................................................67

Figure 7: Coconut Plantation on the Island of Santo in Vanuatu ...............................................67

\section{LIST OF TABLES}

Table 1: High Level Analysis of Several Potential Climate Change Mitigation Activities in

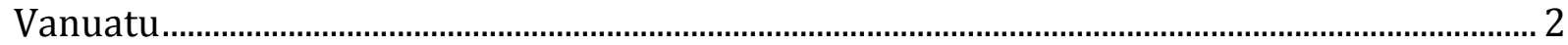

Table 2: Vanuatu Value of Imports and Exports in 2005 (Vanuatu National Statistics

Office 2006)

Table 3: Nominal Price Projection of Crude Oil and Fossil Diesel (Adapted from International Energy Agency 2007b) . 
Table 4: Projected Price of Natural Gas and Methanol (SOurce: IEA (2007b) and authors

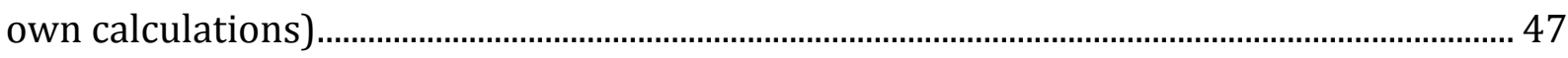

Table 5: Operating Cost Sources (USD per Litre) ……………………………………………... 49

Table 6: Financial Analysis Results (Thousands of USD) ……………………………………. 51

Table 7: Cost and Benefits of the Type of Biodiesel Project.......................................................57

Table 8: Baseline Data ......................................................................................................................... 63

Table 9: Volume of Certified Emission Reductions..................................................................... 70

Table 10: List of Interviewees............................................................................................................ 87 



\section{INTRODUCTION}

Many people have recently said that the threat of climate change is the most serious issue humanity is currently facing. Because of this, many of the specific details of the broad and complex climate change issue are receiving a great deal of exposure and attention in the media, academic publishing, and the political forum. In a speech in July 2007 the United Nations Secretary-General Ban Ki-moon said that "The time has come for decisive action on climate change" (Ki-moon 2007).

The Secretariat of the Pacific Regional Environment Programme (SPREP) has published a series of national reports called "Pacific Regional Energy Assessments". The Vanuatu National Report recommended that a feasibility study be carried out on coconut oil based bio-fuel being used to replace a significant amount of distillate imports for power generation and transport. In 2007 the Managing Director of the only electricity generator in Vanuatu said that the choice between fossil diesel and biodiesel is only a matter of price; however, he was not aware of how international climate change mitigation efforts could enable a biofuel project in Vanuatu to be successful.

Table 1 shows the author's own high level assessment of several climate change mitigation opportunities in Vanuatu. This high level view of the opportunities shows that biodiesel production for grid connected electricity generation may have relatively greater benefit, with fewer constraints than the other opportunities. 
TABLE 1: HIGH LEVEL ANALYSIS OF SEVERAL POTENTIAL CLIMATE CHANGE MITIGATION ACTIVITIES IN VANUATU

\begin{tabular}{|c|c|c|c|c|c|c|}
\hline Project & Technology & $\begin{array}{c}\text { Development } \\
\text { benefits }\end{array}$ & $\begin{array}{c}\text { Capital } \\
\text { investment } \\
\text { required }\end{array}$ & $\begin{array}{c}\text { Likely public } \\
\text { support }\end{array}$ & $\begin{array}{c}\text { Existing } \\
\text { infrastructure? }\end{array}$ & $\begin{array}{c}\text { Scale to } \\
\text { cover CDM } \\
\text { transaction } \\
\text { costs? }\end{array}$ \\
\hline $\begin{array}{c}\text { Land } \\
\text { transport fuel } \\
\text { swap to } \\
\text { biodiesel }\end{array}$ & $\begin{array}{l}\text { Existing, } \\
\text { partially } \\
\text { proven }\end{array}$ & High & Low & Tentative & Most & $\begin{array}{c}\text { Large } \\
\text { enough }\end{array}$ \\
\hline $\begin{array}{c}\text { Vila } \\
\text { electricity } \\
\text { generation } \\
\text { fuel swap to } \\
\text { biodiesel }\end{array}$ & $\begin{array}{l}\text { Existing, } \\
\text { proven }\end{array}$ & High & Low & High & Most & $\begin{array}{l}\text { Large } \\
\text { enough }\end{array}$ \\
\hline $\begin{array}{l}\text { Vila new } \\
\text { renewable } \\
\text { electricity } \\
\text { generator }\end{array}$ & $\begin{array}{l}\text { Existing, } \\
\text { proven }\end{array}$ & Medium & High & Reasonable & Some & $\begin{array}{l}\text { Possibly } \\
\text { large } \\
\text { enough }\end{array}$ \\
\hline $\begin{array}{c}\text { Methane } \\
\text { capture at } \\
\text { Efate abatoir }\end{array}$ & $\begin{array}{l}\text { Existing, } \\
\text { proven }\end{array}$ & Low & High & Unconcerned & Some & Too small \\
\hline $\begin{array}{c}\text { Methane } \\
\text { capture at } \\
\text { Efate landfill }\end{array}$ & $\begin{array}{l}\text { Existing, } \\
\text { proven }\end{array}$ & Low & High & Unconcerned & None & Too small \\
\hline $\begin{array}{c}\text { Rural } \\
\text { Electrification } \\
\text { master plan }\end{array}$ & $\begin{array}{c}\text { Variety of } \\
\text { technologies; } \\
\text { existing and } \\
\text { partially } \\
\text { proven }\end{array}$ & High & High & High & None & $\begin{array}{c}\text { Large } \\
\text { enough if } \\
\text { projects are } \\
\text { bundled }\end{array}$ \\
\hline
\end{tabular}

The grid electricity available in Port Vila is generated from several diesel generators, which may be able to be run on biodiesel if adequate volumes could be reliably sourced. Because bio-fuels are a renewable fuel this project could be a climate change mitigation project and as such it may be eligible for carbon financing under the clean development mechanism (CDM) of the Kyoto Protocol. Despite the financial incentive of the CDM and the many benefits to Vanuatu of the project, biodiesel is not currently produced or used on a large scale in Vanuatu. Vanuatu has many coconut plantations that produce copra for the declining international market, and copra is therefore an important income earner for many Ni-Vanuatu, particularly on the island of Santo. Because coconut oil is a type of vegetable oil, it can be used to produce biodiesel using a method called transesterification. If the project would be economically viable given carbon finance, 
then there must be non-economic barriers that have prevented the project from being initiated if one assumes that the potential users of carbon finance are aware of the carbon finance system. Aside from economic barriers, Ralph Sims broadly puts barriers to bio-energy projects into five other categories: technical, environmental, social, policy, and perception (Sims 2002).

As well as reducing greenhouse gas emission a fuel swap - replacing fossil fuel use with a renewable fuel - is likely to have many local benefits such as stability of price and demand for Vanuatu copra growers. Despite the potential benefits, a fuel swap has not yet been initiated in Vanuatu. This research will look at whether the CDM provides sufficient incentive to initiate a fuel swap, or whether further barriers would need to be addressed. There may be several different types of barriers, such as economic, political, practical, international policy, national policy, public opinion, and others. These barriers should be taken into account to reduce market failure and increase the uptake of renewable energy.

The failure so far for this potential climate change mitigation project, which is shown in this thesis to be likely to be economically viable, to materialise is an example of the difficulty faced by the signatory countries of the United Nations Framework Convention on Climate Change (UNFCCC) to ensure that reasonable efforts are made to apply climate change mitigation technology as stated in Paragraph One, Article 12 of the UNFCCC, across a wide spectrum of geographical diversity. There is some consensus in the Pacific that the CDM is too cumbersome to be relevant to the relatively small climate change mitigation projects that are possible in Pacific Islands. Therefore, those given the responsibility of promoting renewable energy projects are looking towards charitable finance from private and overseas development aid (ODA) styled public funds to invest in renewable energy. It would be beneficial to the Pacific Islands if renewable energy projects that were economic in their own right, or with the additional opportunity of carbon finance, are encouraged by governments and regional institutions. The use of biodiesel in the diesel generators at Vila and Tagabe appears to be a very plausible and significant climate change mitigation project for Vanuatu, yet it is not happening. The biodiesel project would generate several additional co-benefits to Vanuatu. Reducing imports of fossil diesel would boost Vanuatu's current account, whilst producing 
biodiesel in Vanuatu would mean value-added economic opportunities and a potentially higher and more stable price for copra growers - many of whom are villagers - relative to the business as usual copra export scenario. It is therefore important to find out what the barriers are to the replacement of fossil diesel with biodiesel, so that solutions can be found and implemented and the CDM can function to its fullest potential locally.

If the project is found to be economically viable, then this research will constitute a useful analysis for encouraging investors, the Vanuatu Government, the Union Electrique Coloniale (Unelco), and a biodiesel supplier to progress on the project. Unelco is the company responsible for generating and retailing electricity in the main towns of Vanuatu. The research will also identify barriers that may be common across many mitigation projects in developing countries, particularly in regards to the transaction costs and eligibility criteria of the CDM. The research will identify policy barriers to a transaction occurring both within the GoV and the Kyoto Protocol. This will show funding agencies what is required in Vanuatu to overcome any such barriers.

Exploring the scale of inclusion of developing countries in post 2012 Kyoto Protocol negotiations are crucial to gaining multilateral support. In 2000 the Vanuatu Council of Ministers agreed to a target date of 2010 for stopping the importation of fossil fuels, particularly through the use of hydrogen technology (Council of Ministers of the Government of Vanuatu 2000).

Climate change is a global issue that will likely cause very serious problems for societies around the world if an international effort on climate change mitigation and adaptation is not successful. The Stern review suggests that climate change under a business as usual scenario would cost a minimum of $5 \%$ of global per-capita consumption and that an appropriate estimate of the cost may be in the upper reaches of 5\%-15\% (Stern 2007).

Climatologists believe that the global warming effect has a certain amount of lag or momentum, which means that the full effects of the present level of emissions will not become apparent for some time. To illustrate this, the fourth IPCC report stated that the world is committed to an expected 0.6 degrees Celsius of warming this century if there was no change to radiative forcing (Intergovernmental Panel on Climate Change 2007). 
It is also well recognised that the economic structure of societies around the world have innate momentum and stickiness (Carlin \& Soskice 2006), meaning that significant changes to limit the emission of atmospheric greenhouse gases will take some time. Combining both of these issues with the seriousness of the climate change threat means that it is imperative for the world to take action to reduce greenhouse gas emissions very swiftly. Stern suggests that, for better or worse, the climate of the second half of the century will be significantly affected by the economic decisions that we make in the next two decades (Stern 2007).

Greenhouse gas emissions can be seen largely from the point of economic decisions. Jeremy Bentham wrote "human beings... are deficient in altruism and therefore require the threat of coercion to encourage them to seek majority interests rather than their own" (Rowland 2005, pp. 44). This is why effective governmental policy must be used to ensure that change occurs. A strong government can overcome the tragedy of the commons if the common costs and benefits are signaled to the public.

Because climate change is a global phenomenon, largely caused by the increasing concentration of greenhouse gases in the atmosphere, the climate system does not geographically distribute the adverse effects in proportion to the amount of greenhouse gases emitted by geographic localities. This means that not only are the costs of climate change not internal to the individual's decision, they are not even internal to a national political system. This makes it a classic case of a 'tragedy of the commons'. Aristotle said "For that which is common to the greatest number has the least care bestowed upon it" in his book named Politics. There is currently much debate regarding the equitability of the geographic spread of greenhouse gas emission reduction responsibility. There is particular debate around the North-South divide. Arguments for responsibility to be shouldered by the global North often centre on the distance between rates of greenhouse gas emissions per capita in the North and South, as well as the higher historical rate of emissions by the global North. It has been suggested that some responsibility must fall on developing countries for several reasons, including large current and historical emission rates. Marco Verweij calls this situation a "North-South stalemate" (Verweij 2006, pp. 33). 
It is very important to formulate policy that is globally acceptable and effective at reducing greenhouse gas emissions in both the North and the South (Verweij 2006). The current primary policy process to encourage this is the United Nations Framework Convention on Climate Change (UNFCCC). The Kyoto Protocol was born out of the UNFCCC process, and ratified in 2004, coming into force in February 2005. All developed countries except the United States of America (USA) have ratified the protocol. The Kyoto Protocol requires ratified developed countries to reach negotiated emission reduction levels. This can be achieved domestically or by meeting a country's deficit by buying carbon credits, via either a joint implementation (JI) project between two developed countries, or via the CDM between a developed country or business and a developing country. Therefore, Nicholas Stern wrote that the Kyoto Protocol is an agreement intended to "create a single global carbon price" (Stern 2007, pp. 541). As of August 24 2007, 763 mitigation projects have been registered under the CDM, with an average annual targeted reduction of greenhouse gases of 162,227,461 tonnes of carbon dioxide equivalent $\left(\mathrm{CO}_{2}\right.$-e) (United Nations Framework Convention on Climate Change 2007). The projects appear to be geographically skewed, suggesting that there are barriers to CDM implementation that have not been internalised into the policy or Kyoto market. Only two of the registered CDM projects are from the Pacific Region and none of the 1629 further projects officially in the pipeline by 27 August 2008 are from the Pacific region (Fenhann 2008). These issues raise the questions of what the barriers to emission reduction projects in developing countries are, and how this affects the suitability of international climate change policy. This is a particularly important issue given the renegotiation of the international policy for the post-2012 period, in which the CDM could be continued, changed, supplemented with other mechanisms, or abandoned.

In 1968 Garett Hardin published an article titled "Tragedy of the Commons". Ever since, academics from various fields have tried to overcome the Tragedy using various tools and analyses. The atmosphere is shaping up to become the Common stage for the Tragedy of climate change. For governmental policy to be successful at avoiding the Tragedy of the Commons it must be able to generate change across a range of industries and geographies. Therefore, the barriers faced by a biofuel industry in Vanuatu are a useful case study of the Kyoto Protocol, exemplifying international work on improving the CDM and attempting to avoid a Tragedy of the Commons. 
Because of the situation of climate change policy research, it is at the forefront of research that often encapsulates the principles of action research and multidisciplinary research. Climate change policy research must take into account research from the fields of public policy, politics, development studies, physical studies (including climatology, paleontology, physical geography, atmospheric physics, and many others), economics, and others. It is also inevitable that some of the research be action research because of the immediacy and unique specificity of the issue.

This research project fits well within this broader context of climate change policy, and more specifically within the current research being undertaken at Victoria University of Wellington. 


\section{VANUATU BIODIESEL ECONOMIC FEASIBILITY}

The literature review on Vanuatu biodiesel economic feasibility was carried out by determining what published literature specifically addresses the economic feasibility of biodiesel production in Vanuatu and searching for a selection of published academic literature addressing the economic feasibility of biodiesel outside of Vanuatu. The research of literature outside Vanuatu is necessary because of the small amount of Vanuatu-specific literature.

The Vanuatu-specific literature search was carried out using the Boolean search phrase 'Vanuatu AND biodiesel AND feasibility' in the following search engines: Google internet search engine, Web of Knowledge database, ScienceDirect database, and the Victoria University of Wellington library catalogue search engine. The broadest possible parameters were used, with no restrictions on date, language, or publication type. The phrase was searched against the broadest possible range of text available in the database and catalogue search engines; this included titles, abstracts, and the full text where possible.

The Vanuatu-specific literature searches found two relevant articles, which were both written by Jan Cloin of SOPAC; they are titled 'Biofuels in the Pacific' and 'Overview of Pacific regional biofuel activities' (Cloin 2005; Cloin 2006).

In 'Biofuels in the Pacific' Cloin (2005) describes the potential for the use of coconut oil across the Pacific generally, followed by an overview of the economic and technical context for the use of coconut oil as a biofuel in the Pacific Islands. In contrast, the article 'Overview of Pacific regional biofuel activities' covers the current situation of the Marshall Islands, Vanuatu, Samoa, Fiji, the Solomon Islands, Kiribati, and Papua New Guinea in terms of the use of coconut oil as a biofuel, without significant economic analysis. Cloin shows that, in all of the countries studied except Fiji, coconut oil is currently blended with fossil fuel and sold on a small scale. However, none of the countries was producing transesterified biodiesel at the time the articles were written. 
At a 2007 workshop regarding future renewable energy in the Pacific, sponsored by the British High Commission in New Zealand, Dr. Geoff Bertram stated in the context of bioenergy that market forces will always prevail and the true litmus test of economic viability is whether bio-energy is being produced. Given that biodiesel is not currently produced in the Pacific, Bertram's comment would suggest that biodiesel is not economically viable. However, responsiveness to market forces is hinged on several assumptions - including unlimited entrepreneurial market actors, unlimited information, and fixed government policy - that are inappropriate assumptions for the situation in Vanuatu. Cloin refers to a World Bank team, without a citation or reference, saying that the production of both ethanol and biodiesel was "not viable at current oil prices" (Cloin 2006, p. 6). This statement does not explain whether or not either biodiesel or ethanol is individually economically viable. With no reference available, it would only be conjecture to suggest that the World Bank actually suggested that neither ethanol nor biodiesel production is economically viable in Fiji.

The geographically generalised literature search was conducted using only the ScienceDirect database. The search phrase used was 'biodiesel AND feasibility' in titles, keywords, and abstracts. This search located eight relevant journal articles.

The eight articles covered a variety of geographic focuses and feedstock types. Six specific locations were researched - Spain (Cruz et al. 2006), Taiwan (Lin et al. 2007), United States of America (Hill et al. 2006; Nelson \& Schrock 2006), Mexico (Islas et al. 2007), and Italy (Caputo \& Pelagagge 2001) - and two papers were either worldwide or geographically generalised (Demirbas 2007; van Kasteren \& Nisworo 2007). The biodiesel feedstock types looked at in the studies are waste cooking oil and waste grease (Cruz et al. 2006; Islas et al. 2007; Lin et al. 2007; van Kasteren \& Nisworo 2007), beef tallow (Nelson \& Schrock 2006), Ethiopian mustard seed oil (Cruz et al. 2006), and soybean oil (Hill et al. 2006). Demirbas' 2007 article discusses the worldwide variety of feedstock types. Demirbas' (2007) brief economic feasibility section was a summary of other studies referring to vegetable oil and animal fat feedstock. The Caputo and Pelagagge (2001) article does not cover a biodiesel feedstock because it focuses on energy uses other than biodiesel for paper industry sludge. Despite not focusing on 
biodiesel, the Caputo and Pelagagge (2001) article is very useful in the context of this Vanuatu study because of the detailed level of economic feasibility analysis.

The Caputo and Pelagagge (2001) study uses a standard net present value formula to assess the profitability of the waste-to-energy plant. Net present value analyses take into account the initial cost of plant construction and the sum of all estimated discounted future cash flows resulting from the operation of the plant. The cash flows are discounted by an interest rate to account for inflation, the time preference of money, and the normal rate of return on investment required by an investor. Caputo and Pelagagge (2001) also include a sensitivity and risk analysis that calculates the change in estimated net present value of the plant that would occur given a more or less optimistic estimation of the financial parameters such as the interest rate and future electricity price.

Van Kasteren and Nisworo (2007) show the use of a break-even analysis as a tool to assess the cost of producing biodiesel. These cost calculations are based on similar assumptions and approach to the Caputo and Pelaggage study. In particular, Caputo and Pelaggage (2001) included the fixed cost of the construction of the biodiesel production facility as well a required return on investment of twenty percent. This cost figure was used to calculate the price at which the biodiesel would have to be sold in order to cover all costs and a normal rate of return on investment.

Nelson and Schrock (2006) did not include a normal level of profit or required rate of return on investment. The fixed capital cost was represented by the inclusion of depreciation. Nelson and Schrock (2006) also included a sensitivity analysis that calculated the production cost given high and low prices of feedstock and glycerin.

The economic analysis in the Spanish study did not account for the fixed capital cost or a required rate of return on the investment (Cruz et al. 2006). Demirbas (2007) and Hill et al. (2006) do not include original economic analysis; the two studies refer to costs calculated in other studies. Given the geographically diverse nature of the two studies, it is inappropriate that they base conclusions on calculations for different specific locations with specific parameters.

The overarching economic feasibility methodology for all of the articles found in the generalised search of the ScienceDirect database is the comparison of calculated 
estimated cost of production with current fossil diesel prices. Some of the articles take the energy-content-per-volume differential between biodiesel and fossil diesel into account. Several of the articles take into account and discuss the implications of various taxation regimes. None of the articles attempt the difficult task of making a comparison between estimated production costs and future projections of oil price. Given a plant life greater than ten years, this may be the largest downfall of the economic analyses.

\section{CARBON FINANCE OPPORTUNITIES}

The literature review on carbon finance opportunities for Vanuatu biodiesel production was carried out in two main steps. The first step was to determine what published literature specifically addresses the carbon finance opportunities for biodiesel production in Vanuatu. The second step was to search for a selection of published academic literature addressing the various related issues of carbon finance for biodiesel production in Vanuatu in a generalised context. The second step is necessary because of the small amount of Vanuatu-specific literature published.

The literature search for publications on the topic of carbon finance for biodiesel in Vanuatu was completed using the following search engines: Google, Web of Knowledge database, ScienceDirect database, and the Victoria University of Wellington library catalogue. The search used a Boolean structure with three keywords or key phrases being used at any one time, joined by the Boolean connector AND. The three keywords or phrases specified the location, technology, and a reference to carbon finance. The location was "Vanuatu"; the technology was "biodiesel OR biofuel OR methyl ester OR biomass OR coconut oil"; and the carbon finance reference was "carbon finance OR carbon credit OR clean development mechanism OR CER OR VER OR voluntary carbon".

The search found two specifically related articles, which were presented at the Asian and Pacific Coconut Community (APCC) forty-first Cocotech meeting: "Preparing the application of coconut plantations to the clean development mechanism of the Kyoto Protocol" (Hamel et al. 2004) and "For a new coconut research and development strategy in Vanuatu" (Labouisse et al. 2004). Both articles suggest that a biofuel industry would encourage Vanuatu's flailing coconut industry and could be supported with the aid of the clean development mechanism. 
The Labouisse et al. (2004) article covers a range of issues facing the Vanuatu coconut industry and details solutions that Vanuatu entities could undertake to improve the Vanuatu coconut plantation industry. The article primarily discusses upstream improvements that could be made in the copra industry such as replanting coconut palm plantations, and strategies to enhance the ecological and financial efficiency of current plantations. The article also discusses some downstream initiatives: "coconut timber", "promoting local consumption of coconut products", and "using coconut oil as a biofuel" (Labouisse et al. 2004).

The Labouisse et al. (2004) article outlines two scenarios for coconut-based biofuel in Vanuatu. In the first scenario the coconut crop is locally processed to straight vegetable oil (SVO) for local use, with the aim of reducing the fossil oil dependence of isolated villages. The SVO could be used for transport or electricity generation (ibid.). The second scenario is of centralized coconut-biofuel production as a substitute for fuel nationally. The biofuel is suggested as being produced as a blend containing sixty percent coconut oil and forty percent diesel. This blend is currently produced at VCPL. Caveats are attached to the second scenario; the article states that more research on the logistical and economic feasibility is required beforehand (ibid.). The article does not promote one scenario - centralized or decentralized biofuel production - over the other, nor does it suggest that the two scenarios are mutually exclusive. The climate change mitigation arising from the use of biomass as an energy source as well as the carbon sequestration ability of coconut plantations is highlighted, and thus it is said that "the coconut palm could eventually be eligible on the world carbon market through the Clean Development Mechanism proposed in the Kyoto Protocol" (ibid., pp. 119).

As its title suggests the article "Preparing the application of coconut plantations to the clean development mechanism of the Kyoto Protocol" from Hamel et al. (2004) assesses the opportunity of the CDM for Vanuatu's coconut palm plantations. The Hamel et al. (2004) article covers non-petroleum fuel production and the carbon sequestration of coconut palm plantations as climate change mitigation activities.

The carbon sequestration refers to the carbon sequestered in the trees and the increase in organic soil matter. However, Hamel et al. (2004) explain that food crops are not eligible for the CDM for aforestation or reforestation during the first commitment period 
(CP1). The article only addresses the carbon credit opportunity from the CDM, and does not discuss whether or not the reforestation of coconut plantations would be eligible for credit on the voluntary carbon market.

The analysis of the opportunity for biofuels frequently cites Caluba et al. (2004), which is an article assessing coconut biodiesel in the Philippines. In particular, Hamel et al. (2004) refer to the statement of Caluba et al. (2004) that 82 to $109 \%$ of the $\mathrm{CO}_{2}$ emissions from using fossil diesel are avoided by replacing fossil diesel with coconut based biodiesel. Hamel et al. (2004) state that Vanuatu has enough coconut plantations to provide three to five times the amount of oil required to entirely replace transport diesel, thus leaving much potential for power generation from coconut fuel as well. Hamel et al. (2004) calculate that biodiesel production would generate 0.95 CERs per hectare of coconut palm plantation, worth 18.90 United States Dollars (USD) given a CER price of 20 USD. If carbon sequestration by perennial crops was an eligible CDM project type, it is estimated that an additional 3.3 CERs would be generated annually per hectare in a twenty-year-old plantation (ibid.). When carbon sequestration and biodiesel production are combined, Hamel et al. (2004) calculate a 12\% increase in the income of copra growers.

The literature search for generally related literature used the same combinations of the three phases, with the exception that one AND was replaced with an OR. Each phrase was repeated with the other AND replaced with an OR. The following three hypothetical article topics give examples of what articles could be found: carbon finance for biodiesel in Peru; carbon finance for wind energy in Vanuatu; macro-economic effects of biodiesel production in Vanuatu. Using the ScienceDirect academic database and the Google internet search engine, eight pieces of literature were found. Only one of these, a report from the Energy Research Centre of the Netherlands, is focussed on biofuels (Bakker 2006). Six articles covered biomass either generally or for specific locations outside of Vanuatu (Balachandra et al. 2006; Bhandari et al. 2004; Gan \& Yu 2008; Gustavsson \& Madlener 2003; Islas et al. 2007; Pokharel 2006). One article covered the role of the CDM in transfer of clean energy in Small Island Developing States (SIDS), with Cape Verde as a case study (Alves et al. 2003). 
The Bakker (2006) report from the Energy Research Centre of the Netherlands summarises the current situation (as of 2006) of biofuels in the CDM as well as an analysis of the barriers, opportunities, and future of biofuels in the CDM. Bakker (2006) points out that, as of June 2006, no biofuel projects were registered. However, six biofuel projects were at the validation stage of the CDM project cycle (ibid). As of March 2008 the situation has changed little, with no biofuel projects registered, and four small scale biodiesel projects at the validation stage (Fenhann 2008). The Bakker (2006) report identifies a number of barriers for biofuels both in a CDM and general context. Most of these are generalised and thus not necessarily relevant to individual projects. Assuming the general barriers - regulatory, technological, market potential, and feedstock supply can be overcome with the help of the CDM, then the primary remaining barrier is the bureaucracy of the CDM project cycle. However, Bakker (2006) points out that the level of bureaucracy - and thus transaction cost - can be reduced if the project is in the small scale category. To be considered small scale, the project must be less than or equal to 15MW according to Decision One of the Conference of the Parties serving as the meeting of the Parties to the Kyoto Protocol at its second session. The fuel swap project proposed in this thesis is within the CDM definition of small scale because the total generation capacity at the Tagabe plant is $8 \mathrm{MW}$. The future of biofuels in the CDM is, according to Bakker (2006), currently uncertain. Bakker (2006) raises the issue of the lead-in time for CDM projects of a few years, meaning that projects are quickly becoming dependent on a post-2012 market for CERs. A post-2012 climate change protocol has not yet been agreed upon, with the result that the demand, supply, and trading rules for CERs after CP1 are currently unknown. 
AIM AND OBJECTIVES

The aim of this research is to analyse the feasibility of using carbon finance to establish a copra based biodiesel refinery in Vanuatu to produce a substitute for the imported fossil diesel for grid-connected electricity generation in Port Vila. The research is driven by the following question: 'What are the barriers to using the Clean Development Mechanism (CDM) to finance a fuel swap from fossil diesel to copra-based biodiesel for grid connected electricity generation in Vanuatu?'

The aim has been broken down into the following objectives:

1. What is the current state of knowledge concerning the viability of grid-connected electricity from biodiesel in Vanuatu international literature?

2. What evidence exists for the evaluation of the financial viability of a fuel swap of Vanuatu's grid connected electricity generation from fossil diesel to copra based biodiesel?

3. What are the practical barriers - if any - to the use of the CDM for the development of copra based biodiesel electricity generation in Vanuatu?

Addressing these questions is intended to provide information capable of assisting the Government of Vanuatu and a potential CDM project developer in their decisions on such a fuel swap project. The information will also be useful in the evaluation of the CDM in terms of its accessibility to small developing countries seeking to use it as intended (i.e. for climate friendly sustainable development). The analysis of any barriers identified in this research is designed to inform policy development for a post-2012 global climate agreement in terms of the accessibility of the CDM in practice.

\section{OVERARCHING METHODOLOGY}

The research is framed as a form of holistic applied human geography, drawing on the academic fields of microeconomics, macroeconomics, environmental studies, public 
policy, developmental studies, and finance. The thesis will draw on a combination of quantitative and qualitative data.

By taking disciplines other than environmental studies into account, the research will reflect what can be achieved from a pragmatic perspective rather than a normative account of what should be achieved from an ideological perspective such as ecological justice or neo-classical economics. However, the overall research is normative by using readily accepted empirical practices of various fields to analyse what should be done. The research draws on the conclusions of positivist research in order to generate normative conclusions.

It is particularly important for the researcher to state their perspective for their approach to the research because of the wide range of people involved in the climate change mitigation discourse. Glover (2006) wrote that "many environmentalists" are discussing the management of the atmosphere from a perspective of environmental justice and equity. However, the issue is also being debated and discussed by economists, politicians, scientists and others. This research is being undertaken from the assumption that existing national and international climate change policy mechanisms are (in principle) sufficient for making substantial progress towards a low carbon future.

The role of the primary investigator has strong elements of participatory research and action research. The primary investigator is not simply observing the situation from the outside but in the role of researcher has an effect on the situation. In particular, the primary investigator will answer questions of interviewees. Whilst traditional ethics would suggest that this is inappropriate behaviour, more modern ethics suggest that this interaction is more ethical as it is empowering to the interviewees and their communities. By freely discussing information with the interviewees the primary investigator is reducing their power over the interviewee. Whilst the primary investigator strives to be unbiased in their offering of information, it is recognised that the information will be somewhat biased by the experience and perspective of the primary investigator.

The participatory nature of the primary investigator makes it necessary for the primary investigator to have an acute self awareness. The research results will not be seen in 
isolation of the primary investigator, but as a result of a process of which the primary investigator was a part. Awareness of their influence will allow the primary investigator better insight into the meaning of the research results.

Pacione (1999) defines applied geography as "the application of geographic knowledge and skills to the resolution of social, economic, and environmental problems" (pp. 3). The latter part of the definition is particularly relevant to this research because this research is attempting to produce information that is the missing link in the process of contribution to addressing the problem of climate change. However, this research does not directly meet the first part of the definition in regard to the use of geographic knowledge and skills. This research uses geographic knowledge and skills to understand and describe the context of the research, but uses multidisciplinary skills to undertake the research. In particular financial analysis is used to assess the theoretical attractiveness of the proposed project to potential investors.

The normative approach of this research assumes the accuracy of accepted positivist research results. The 'normative' is strongly linked to the motivation of participatory research, in that the normative assumes that something, often human intervention, is missing. The aim of a normative researcher is to be the missing link through the provision of knowledge in order to fulfill the possibilities and opportunities presented for the betterment of society.

The holistic approach is useful for applied geography as it is to be used in real world situations, outside of a controlled laboratory. This means that the primary investigator may learn from and report on observations that are clearly relevant to the aim of the research, but may fall outside of the prescribed objectives and their relative methodologies.

The research was primarily carried out by means of semi-structured interviews in combination with analysis of financial data relevant to the task of a fuel swap. The interviews with all stakeholders that were contacted covered a series of open-ended questions that were used to prompt discussions on the interviewees' thoughts on biofuels in Vanuatu (such as 'What do you think the barriers to a biofuels industry in Vanuatu might be?'). When relevant, the stakeholder interviewees were asked specific 
questions that were required for the components of the Net Present Value (NPV) model or to further understand the constraints and opportunities (such as discussing shipping logistics with a coconut oil exporter). For information that was not available from the stakeholders interviewed, the information was sought from the most reputable and transparent source available, such as export data from the Statistics Office of the Vanuatu Government. A list of the people who were interviewed and their qualifications for being considered a relevant expert to the project is included as Appendix 1 and a schedule of

the interviews is given in Appendix 3. The interviews were carried out with the approval of the Human Ethics Committee of Victoria University of Wellington, which is shown in Appendix 2.

\section{ECONOMIC FEASIBILITY METHODOLOGY}

The economic feasibility of the fuel swap from fossil diesel to biodiesel at Unelco's Tagabe plant using locally sourced biodiesel was assessed using a net present value comparison. The net present value was calculated from the perspective of an investor in a Vanuatu biodiesel production plant.

In an accounting text book that is prescribed for courses in several New Zealand and Australian Universities, Bazley et al. (2001) defined the investment "decision rule" as:

"The net present value (NPV) method is the recommended method for evaluating capital investment decisions" (Bazley et al. 2001, pp. 379).

This is confirmed by Allen et al. (2006), which suggests that the NPV method of investment analysis is widely considered best practice.

The relevant net present value in this study is the overall net present value of building and operating a biodiesel plant in Vanuatu. The net present value is the sum of the discounted projected cash flows, including start up costs. The discount factor is the real expected rate of return (the rate of return that investors generally expect from capital investment in the economy), which is applied to the nominal cash flow projection.

The model will use annual data, thus Equation 1 - modified from Bazley et al. (2001) represents the NPV for this model. 


$$
N P V=\sum\left(P_{n} \frac{1}{(1+R)^{n}}\right)-\sum\left(C_{i, n} \frac{1}{(1+R)^{n}}\right)
$$

Where: $\quad P_{n}$ is the production revenue in year $n$ of the plant's life;

$\mathrm{C}_{\mathrm{i}, \mathrm{n}}$ is the cost of variable $i$ (e.g. methanol) in year $n$ of the plant's life; and

$\mathrm{R}$ is the discount rate, set at the minimum required rate of return for reasonable profit.

The key assumption of the model is that the biodiesel producer will only be able to sell the biodiesel to Unelco if the price per unit of energy output of biodiesel is equal to or lower than that of imported fossil diesel. The price of biodiesel and fossil diesel are assumed to be compared by Unelco on a delivered tax-free basis. This assumes that biodiesel would be treated the same as fossil diesel by the Department of Customs and Internal Revenue. This is a strong assumption because fossil diesel used by Unelco for electricity generation currently does not attract import taxes. Thus the model inherently assumes the equal tax treatment of imported fossil diesel and domestic biodiesel. This also means that the tax revenue of the Government of Vanuatu would not decrease due to the proposed fuel swap.

The key data used are: fossil diesel price projection, coconut oil price projection, biodiesel plant capital investment, biodiesel plant operating cost, distribution costs, exchange rate projection, and methanol price projection. The net present value model will also need to use the net calorific values of biodiesel and fossil diesel, the greenhouse gas emission reduction rate for biodiesel when compared to fossil diesel, and an appropriate discount rate.

\section{CARBON FINANCE OPPORTUNITIES METHODOLOGY}

To find whether the fuel swap project could be eligible for carbon finance, the fuel swap scenario was analysed from the perspective of the CDM in particular, as the CDM is the most common and respected form of carbon finance for this type of activity in a developing country. To do this the project design document (PDD) template is analysed 
as to whether it could be successfully completed with the project. To be able to complete a PDD the project will need to meet the criteria of the CDM. The two main criteria of the CDM are:

1. a suitable methodology for baseline and monitoring, and

2. the reasoning to pass the additionality test.

The most common reasons for the CDM Executive Board (EB) rejecting a CDM project application is failure to meet the additionality criteria or failure to supply an adequate methodology.

It is impossible to fully know whether or not the CDM EB would register and validate the Vanuatu project without submitting an application, however, to check the likelihood of success, a CDM expert was asked about the suitability of the fuel swap project under CDM. CDM Consultant Robert O'Sullivan who works with many Designated National Authorities (DNAs) and project developers was interviewed regarding the suitability of the fuel swap project, particularly in terms of additionality and baseline and monitoring methodology. 


\section{BIODIESEL}

\section{INTRODUCTION}

Biodiesel is a fuel with very similar properties to fossil diesel; however it is produced from vegetable or animal oils by a process called transesterification.

The close similarity between biodiesel and fossil diesel aids the introduction of biodiesel into the energy market. While many bio-energy products require specific end-use technology, biodiesel can replace fossil diesel in stationary engines as well as vehicle engines without engine modification. The infrastructure designed for fossil diesel including shipping, storage, and pipelines can also be used for biodiesel without modification.

The IEA estimated that in 2007 biodiesel represented slightly more than one percent of world diesel use (International Energy Agency 2007a). The primary use of diesel fuel worldwide is transport. Other uses include stationary machinery (e.g. for manufacturing), small scale direct use electricity generation and national grid connected electricity generation. The 2007 IEA reference scenario projects global oil use to increase by around 1.3\% per annum between 2006 and 2030 (International Energy Agency 2007b). This increase contradicts the requirements of a reduction in fossil fuel use to avoid dangerous climate change. Biodiesel can help this situation because when it is produced in the right circumstances it produces a significantly lower net emission of greenhouse gases compared to fossil diesel. This is one reason why several Governments - including New Zealand, USA, and EU - have introduced policy that provides incentives for biofuel producers such as a subsidy or a mandatory sales level.

\section{METHOD OF PRODUCTION}

The production process of biodiesel from biogenic oil or fat is a simple industrial process. The chemical reaction occurs between the fat or oil and methanol; the reaction can be carried out in large tanks. To improve the efficiency of the reaction, heat and a 
catalyst are used. The reaction results in several outputs: biodiesel, glycerine, the catalyst, and excess methanol. Equation 2 shows a typical chemical reaction, resulting in biodiesel - the oxygenated long chain hydrocarbon known as a fatty ester (Clements et al. 2006, pp. 4).

EQUATION 2: TYPICAL BIODIESEL REACTION

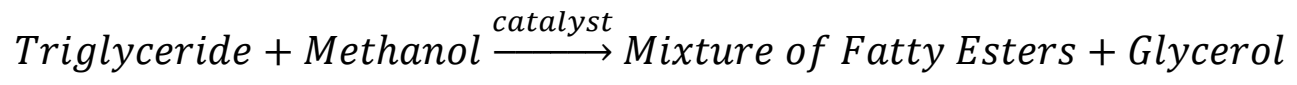

The transesterification process can be carried out at several scales from backyard production for individual use through to plants that produce over 100 million litres per year. Figure 1 below is of the Naturol Bioenergy biodiesel plant in Kakinada, India, which has an annual production capacity of over 100 million litres per year (Biofuels International 2007).

FIGURE 1: BIODIESEL PLANT IN KAKINADA, INDIA

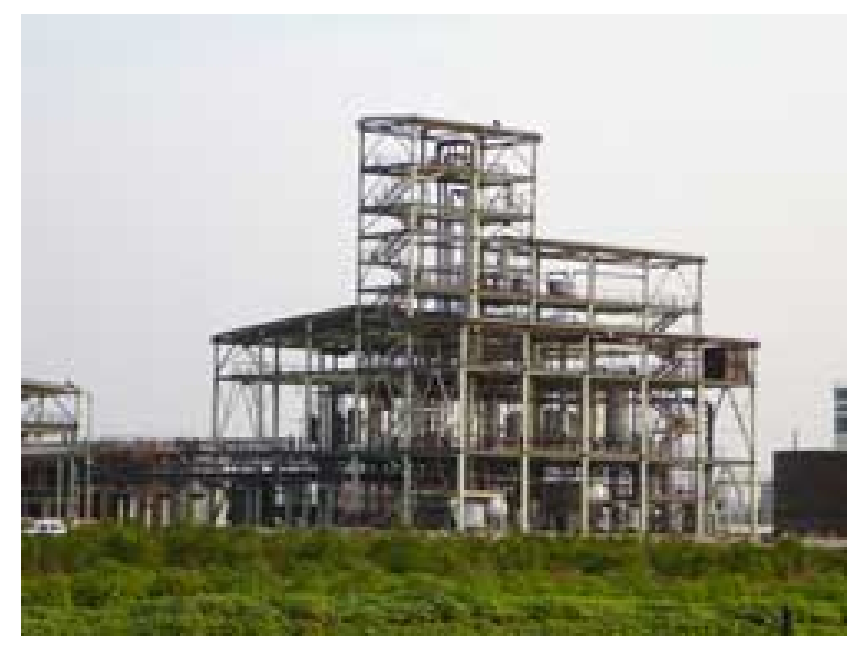

(Photo sourced from Biofuels International 2007).

\section{WORLDWIDE USE AND CURRENT EXAMPLES OF BIOFUEL PRODUCTION AND USE}

The benefits to the environment of a reduction in fossil fuel use and the economic and strategic benefits of energy independence have been the predominant drivers of the worldwide production of biofuels. An exception is Brazil, which has a long established cane sugar based ethanol industry that is now successful because it is cheaper than fossil petroleum. Biogenic sourced ethanol is a more common biofuel than biodiesel because 
of the plentiful supply of feedstocks. The reason for the plentiful supply of feedstocks is that the feedstocks are also common staple foods such as maize. It was anticipated that ethanol would make up 78\% of the world biofuel production in 2007 (International Energy Agency 2007a).

The geographic distribution of biofuel production is widely spread, but has three main consumers. The USA produces and consumes a large amount of ethanol - enough to replace 14 billion litres of petroleum in 2006 (United States of America Energy Information Administration 2008) - because of the subsidies that the USA federal government has put in place for corn growers to decrease the country's net dependence on foreign oil. As mentioned earlier Brazil has a well established ethanol industry based in sugar cane because of its price competitiveness with fossil petroleum. The other main consumer of biofuel is the members of the EU, which are progressively introducing mandatory biofuel sales targets as a way of combating growing greenhouse gas emissions. These targets have led to the development of a local biodiesel industry, mainly based on rapeseed oil as well as the importation of biofuels. Members of the EU import both ethanol and biodiesel from tropical countries, as these countries typically produce the cheapest fuels from cheap land and labour prices, lax business rules, and rapid biomass growth rates. The largest contributing feedstocks from the tropics are sugar cane based ethanol and palm oil based biodiesel.

Research into future biofuel production is focusing on ligno cellulose as a feedstock for ethanol, algae as a feedstock for biodiesel, and jatropha oil as a feedstock for biodiesel and jet fuel. Algae based biodiesel would use a modified transesterification process, which is currently being researched. Research is being carried out into production of second generation ethanol, which is produced by using enzymes to break down the fibres in ligno cellulose before fermenting to create methanol. An example of this is the offcuts of the forestry industry. While these are both very promising, neither process has yet been proven commercially. Jatropha oil is promising due to the jatropha plant's ability to grow in soil that is too poor quality to support food crops. Jatropha oil has commercially been used as a feedstock for biodiesel in a transesterification process but is still in the early stages of being proven as a substitute for jet fuel. 
When considering the whole life-cycle of energy sources, biodiesel may release less greenhouse gases on a net basis than fossil diesel.

The primary reason for this difference is that fossil fuels arise from photosynthetic carbon that has accumulated in reservoirs (e.g. oil fields) and been stored outside the short term carbon cycle for tens and sometimes hundreds of millions of years. Biofuels on the other hand are generated from photosynthesis in the short term carbon cycle where the carbon has been taken out of the atmosphere very recently (years ago) and then released back to the atmosphere via combustion. Whereas fossil fuels introduce new carbon to the short term carbon cycle, biofuels are potentially carbon neutral from a geo-physiological point of view. The carbon neutrality of a biofuel depends on the way that the bio-energy crop is produced. Some bio-energy crops have a very large carbon footprint because they have arisen from the deforestation of tropical forests - such biofuel is less likely to be carbon neutral or capable of making a positive contribution to climate change mitigation.

An example of biofuel production is the use of rapeseed oil to produce biodiesel. The seeds are harvested from the plants and pressed to produce oil. The byproduct is often used as animal feed. The plants remain and grow more seeds after harvesting, resulting in a constant average carbon stock for the crop. However, there are also many factors that can affect the overall carbon flux of an energy crop plantation including soil management and tilling, fertilizer use, and the destruction of forest to make way for agriculture.

\section{BIODIESEL CONTROVERSIES}

The main controversies surrounding biodiesel relate to the land required for growing biodiesel feedstock crops. Other controversies relate to the economic and political influences of the production investment decision as well as the end use performance of biodiesel when compared to fossil diesel. 
A debate on land use for energy crops has been ongoing in political, media, and NGO spheres. The debate is primarily focused on the opportunity cost of using large tracts of land for energy crops, but also raises other issues.

"Concerns about the sustainability of biofuels are growing, including land-use and deforestation issues, water use, human rights concerns, and the "food versus fuel" debate". (Bradley and Childs 2007, pp. 32).

The alternative land uses raised in the debate include food crops in agricultural systems; biodiversity in natural ecosystems; carbon storage in forests; local community economic and subsistence activity. Whilst individual land use decisions are often economically based, the overall debate is often not economic. When viewed on a large scale, the trends in land use have a large effect on biodiversity, greenhouse gas emissions, and human rights. Currently there is no reliable or consistent economic incentive on any of these three things.

The implementation of the Kyoto Protocol is generating a price for carbon as represented by the trade of CERs, AAUs, ERUs, and RMUs. However, the coverage of the Kyoto Protocol is incomplete in the 2008-2012 period, and in particular does not cover deforestation in developing countries. The carbon price of using fossil fuel in Annex I countries whilst there is no price on GHG emissions from deforestation or nitrogenbased fertiliser in Annex II countries results in a mismatch of economic incentive, with more conversion of land from forest to energy crops than is optimal.

The dearth of economic incentive for the protection of biodiversity means that the global interest in protecting the world's remaining biodiversity is not taken into account when an individual person or business decides on the best use of land. An example that has been commonly referred to in the political, media, and NGO spheres is the destruction of orangutan habitat in Indonesia for the development of palm oil plantations, which can be used as a feedstock for biodiesel.

The large scale conversion of rainforest to biodiesel stock plantations can also be considered as human habitat destruction. Many of the world's largest rainforests support indigenous communities that depend on the rainforest for food, water, shelter, and fuel, as well as spirituality and culture. Rainforests around the world are at threat of 
deforestation, one major driver of which is the demand for biofuel feedstock such as cane sugar and palm oil.

Due to the geographically diverse range of negative externalities of the production of biodiesel feedstock, a holistic cost-benefit analysis would need to be location-specific. However, several national governments have introduced policy to support biofuels that is not specific to the place or process of production. An example is the recent controversial announcement of the EU to aim for a renewable energy target of twenty percent by 2020, which is to include a biofuel target of ten percent (European Commission 2008). Because of the inconsistency of economic incentive over negative externalities of production and consumption, there may be some cases in which the negative externalities of production that are not accounted for (i.e. deforestation in Annex II countries) may be greater than the reduced negative externality of the consumption of fossil fuel in Annex I countries that is accounted for via the Kyoto Protocol.

Despite the controversies, many Governments are developing and implementing policies to support biofuels. The reasons for this support are not limited to greenhouse gas emissions; the reasons also include the reduction of oil dependence and increase in energy security, improvement of the country's balance of trade, and improving rural incomes (Bradley and Childs 2007).

KYOTO PROTOCOL AND THE CLEAN DEVELOPMENT MECHANISM

The CDM is a crucial mechanism of the Kyoto Protocol, which was written in 1997 at the third Conference of the Parties (COP3) to the United Nations Framework Convention on Climate Change (UNFCCC). The Kyoto Protocol is a binding protocol that limits the allowed total CP1 greenhouse gas emissions of the group of participating developed countries to five percent less than the total in 1990.

The level of responsibility of individual countries to contribute to the overall reduction in greenhouse gas emissions was negotiated amongst the parties, with each UNFCCC Annex I party given a limit relative to their 1990 level of emissions. In order to improve the economic efficiency of the protocol, the trading of Assigned Amount Units (AAUs) is 
allowed. Under intergovernmental emissions trading rules one Annex I country (Country A) may under comply with their binding emissions reduction target (through domestic abatement), but then buy surplus units (AAUs) from another Annex I country (Country B) that has over complied with their binding target. The inclusion of carbon trading encourages least cost emission reductions, no matter which Annex I country has the cheapest potential emission reduction opportunities.

The CDM furthers the economic efficiency of the Kyoto Protocol by allowing Annex I countries to find least cost emission reduction opportunities in developing countries (that do not have any binding emissions reduction obligations). Here, a project to reduce emissions or generate removals from sinks is carried out in a developing country, generating the appropriate number of CERs, each of which correspond to one tonne of $\mathrm{CO}_{2}$ equivalent emissions reduction. The resulting CERs can be bought by an Annex I country to help meet their compliance obligations. To maintain the integrity of the overall emission reduction system, the CDM projects must be 'additional'. The test of additionality is to evaluate whether the project would not have occurred in the absence of CDM carbon finance. The CERs that the project generates are the difference between the 'business-as-usual' baseline and the new reduced level of emissions.

The CDM has been well supported because it has other co-benefits as well as the initial greenhouse gas emission reduction. One of the benefits is the financial support of sustainable development in developing countries. Often the projects are commercial projects, generating employment opportunities for local communities. Sustainability of projects is ensured by the sustainability test, which the host country's Designated National Authority (DNA) must approve according to national policy associated with CDM activities. The CDM is also a method of transferring technology to developing countries. Many of the countries will develop skills and experience with technology such as wind turbines as a direct result of the CDM. This may make it more likely for low emission technology to be used elsewhere in the country, and for developing countries to further their involvement in the UNFCCC in future commitment periods. 
Carbon finance refers to the trading of the value of carbon. Trading can occur in the compliance or voluntary markets. The compliance markets are the markets created by the greenhouse gas emission cap and trade systems. The voluntary markets are alternative markets created by businesses, institutions, individuals, and even countries who wish to voluntarily offset their emissions as part of a carbon neutrality program, and linked with corporate social responsibility (CSR), consumer demand, and a desire for market share. The magnitude of the voluntary market has a partially inverse correlation to the compliance market. The Chicago Climate Exchange, for example, is a very large voluntary carbon market, whilst there is not compliance trading in the USA.

The largest compliance market in 2008 is the market created by the Kyoto Protocol, and the largest compliance market before 2008 was the European Union Emissions Trading Scheme (EU ETS). The EU ETS has been continually improving credit fungibility with the Kyoto Protocol so that the markets are linked and carbon credits can be transferred from one market to the other. In particular, participants of the EU ETS are able to use many types of Kyoto Protocol CERs to meet their binding targets - although meeting a binding target will commonly first require 'in-house' abatement and the purchasing of emission units only for those emissions reductions that are too expensive to undertake through abatement.

Participating countries of the Kyoto Protocol can trade three different types of carbon credits in order to reach their target. The three types of credits that can be traded are assigned amount units (AAUs), certified emission reductions (CERs) generated via the $\mathrm{CDM}$, and emission reduction units (ERUs) generated via the JI mechanism. All three types of Kyoto compliant credits represent one tonne of carbon dioxide or carbon dioxide equivalent. Carbon dioxide equivalent is a metric of greenhouse gases covered by the Kyoto Protocol of varying Global Warming Potentials (GWP) but translated into a value equivalent to carbon dioxide over a one hundred year period. For example, one tonne of a gas that is 40 times more potent than carbon dioxide would be translated into 40 tonnes of $\mathrm{CO}_{2} \mathrm{e}$. AAUs are the allowance of credits that each participating Annex I country has negotiated relative to their 1990 level of greenhouse gas emissions. ERUs represent project-based reduction (or sink removal) units of greenhouse gas relative to 
'business-as-usual' baseline under the joint implementation (JI) mechanism. JI projects are projects that are carried out by one participating Annex I country within the border of another Annex I country. JI has been developed primarily for Eastern European countries. Under JI the host country remains liable for 'business-as-usual' emissions, while the foreign country undertaking the activity receives the recognition for the emission reductions by receiving ERUs. CERs are the carbon credits that are allocated to CDM projects that are additional emission reduction projects undertaken in non-Annex I countries. The traders of carbon credits may be Annex I governments, CDM project developers, and secondary traders. The secondary traders buy and sell carbon credits in order to make a profit from any arbitrage opportunities, which will make the market less volatile.

The voluntary markets are markets in which voluntary emission reductions (VERs) are generated and sold to entities to voluntarily offset their emissions. In order to be additional under the current rules of the most commonly used standards, the VERs must be generated from activities that are outside of the carbon accounting of the compliance market. Examples of projects within Annex I countries include carbon sequestration from crops and regeneration of native forests, which are excluded from many countries' carbon accounting rules. CDM type projects can also be eligible to generate voluntary carbon credits. There are a number of organisations that have auditable standards for voluntary carbon reduction projects. This means that a range of quality of carbon credits is available to consumers arising from different standards. Some standards require less stringent monitoring than CERs, whilst some standards have more stringent elements such as sustainability tests. The most common use of voluntary carbon credits is to entirely offset a set of greenhouse gas emissions so that set of activity can be considered carbon neutral. Examples of this can include an environmentally conscious household offsetting their total annual emissions, and a business can offset their emissions and use their carbon neutral status as a marketing strategy to environmentally conscious consumers. 
Vanuatu is an independently governed Melanesian archipelago of 83 islands in the South West Pacific. Vanuatu had a population of approximately 221,000 in 2006 - the majority of whom are indigenous Ni-Vans - widely distributed across the islands (World Bank 2008). There is however a concentration of population in the capital of the Vanuatu, Port Vila. The Y-shaped republic is represented in the map Figure 2.

FIGURE 2: MAP OF VANUATU (SOURCE: MAPQUEST 2006)

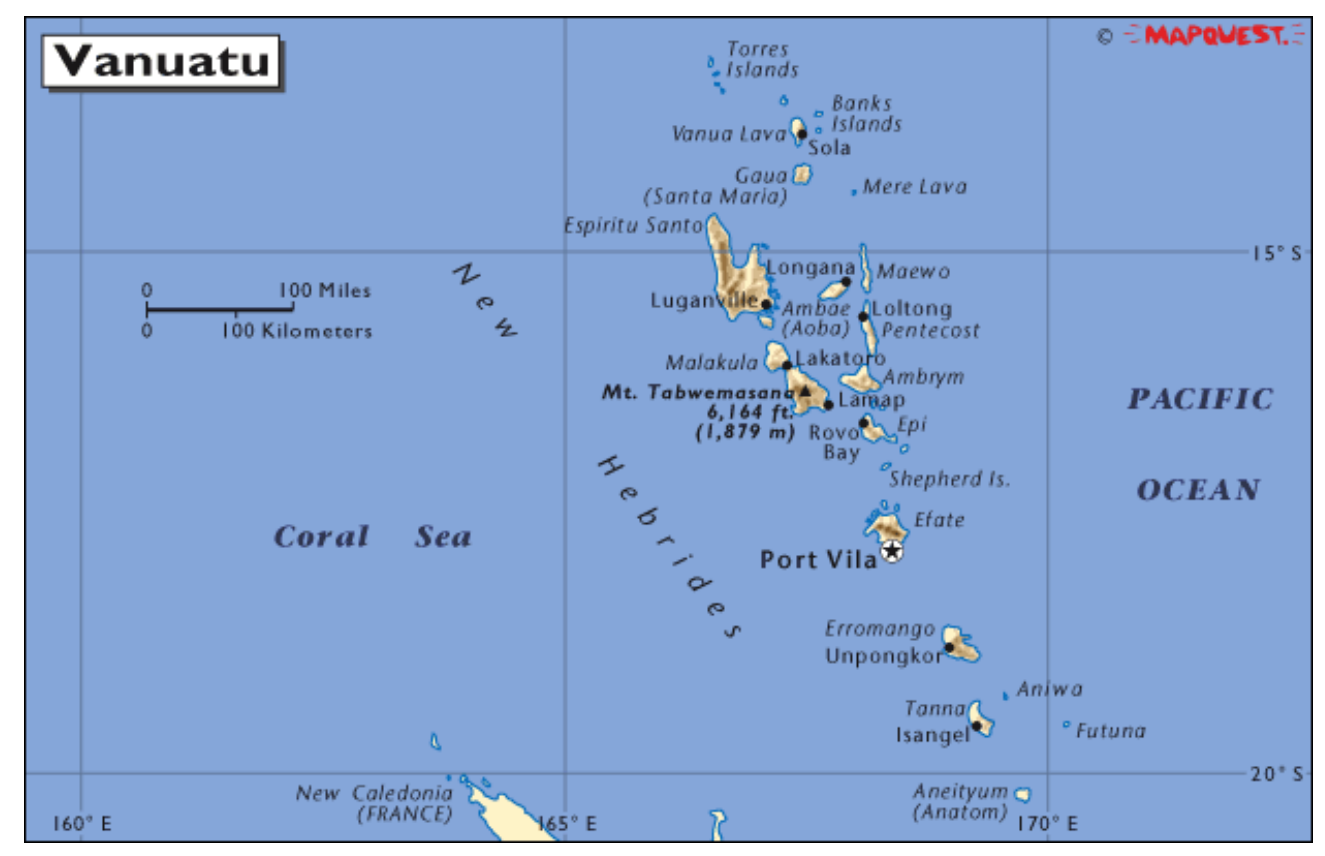

The country gained independence from condominium status under dual colonialists France and Britain in 1980. The country is defined as a least developed country by the UN. However, despite a low gross domestic product per capita Vanuatu is fortunate to have been reasonably free of conflict; have a climate that supports successful agriculture; have a vibrant culture; and does not suffer from overpopulation. The country's trade in terms of imports and exports is given in Table 2. 
TABLE 2: VANUATU VALUE OF IMPORTS AND EXPORTS IN 2005 (VANUATU NATIONAL STATISTICS OFFICE 2006)

\begin{tabular}{|c|c|c|c|c|c|}
\hline \multicolumn{3}{|c|}{ Exports } & \multicolumn{3}{|c|}{ Imports } \\
\hline & $\begin{array}{c}\text { Value } \\
\text { Million Vatu }\end{array}$ & $\begin{array}{c}\text { Value } \\
\text { Thousand } \\
\text { USD }\end{array}$ & & $\begin{array}{c}\text { Value } \\
\text { Million Vatu }\end{array}$ & $\begin{array}{c}\text { Value } \\
\text { Thousand } \\
\text { USD }\end{array}$ \\
\hline Copra & 126 & 1,109 & $\begin{array}{l}\text { Food and } \\
\text { animals }\end{array}$ & 2,863 & 25,194 \\
\hline Coconut Oil & 733 & 6,450 & $\begin{array}{c}\text { Beverages and } \\
\text { tobacco }\end{array}$ & 437 & 3,846 \\
\hline Cocoa & 181 & 1,593 & Raw materials & 241 & 2,120 \\
\hline Beef & 302 & 2,658 & Mineral Fuels & 1,837 & 16,166 \\
\hline Shells & 57 & 503 & Oils, fats, waxes & 73 & 642 \\
\hline Timber & 203 & 1,786 & Chemicals & 2,581 & 22,713 \\
\hline Kava & 477 & 4,198 & $\begin{array}{c}\text { Basic } \\
\text { manufactures }\end{array}$ & 2,369 & 20,847 \\
\hline $\begin{array}{l}\text { Coconut } \\
\text { Meal }\end{array}$ & 85 & 748 & $\begin{array}{l}\text { Machines, } \\
\text { transport } \\
\text { equipment }\end{array}$ & 3,422 & 30,114 \\
\hline Live Cattle & 56 & 493 & $\begin{array}{l}\text { Miscellaneous } \\
\text { manufactured } \\
\text { goods }\end{array}$ & 1,930 & 16,984 \\
\hline Other & 616 & 5,421 & Goods N.E.C. & 395 & 3,476 \\
\hline $\begin{array}{c}\text { TOTAL } \\
\text { EXPORTS }\end{array}$ & 2,836 & 24,957 & TOTAL IMPORTS & 16,148 & 142,102 \\
\hline
\end{tabular}

As can be seen, the use of copra for biodiesel production as a substitute for fossil diesel will have a significant effect on the Vanuatu economy. A large proportion of the current coconut plantations were planted in the 1980s, and few are being replanted. While the final export of copra or coconut oil is very centralized, the coconut farming and initial processing into copra is very decentralized.

Figure 3 shows an example of a typical small scale copra drying facility on the Island of Espiritu Santo. 


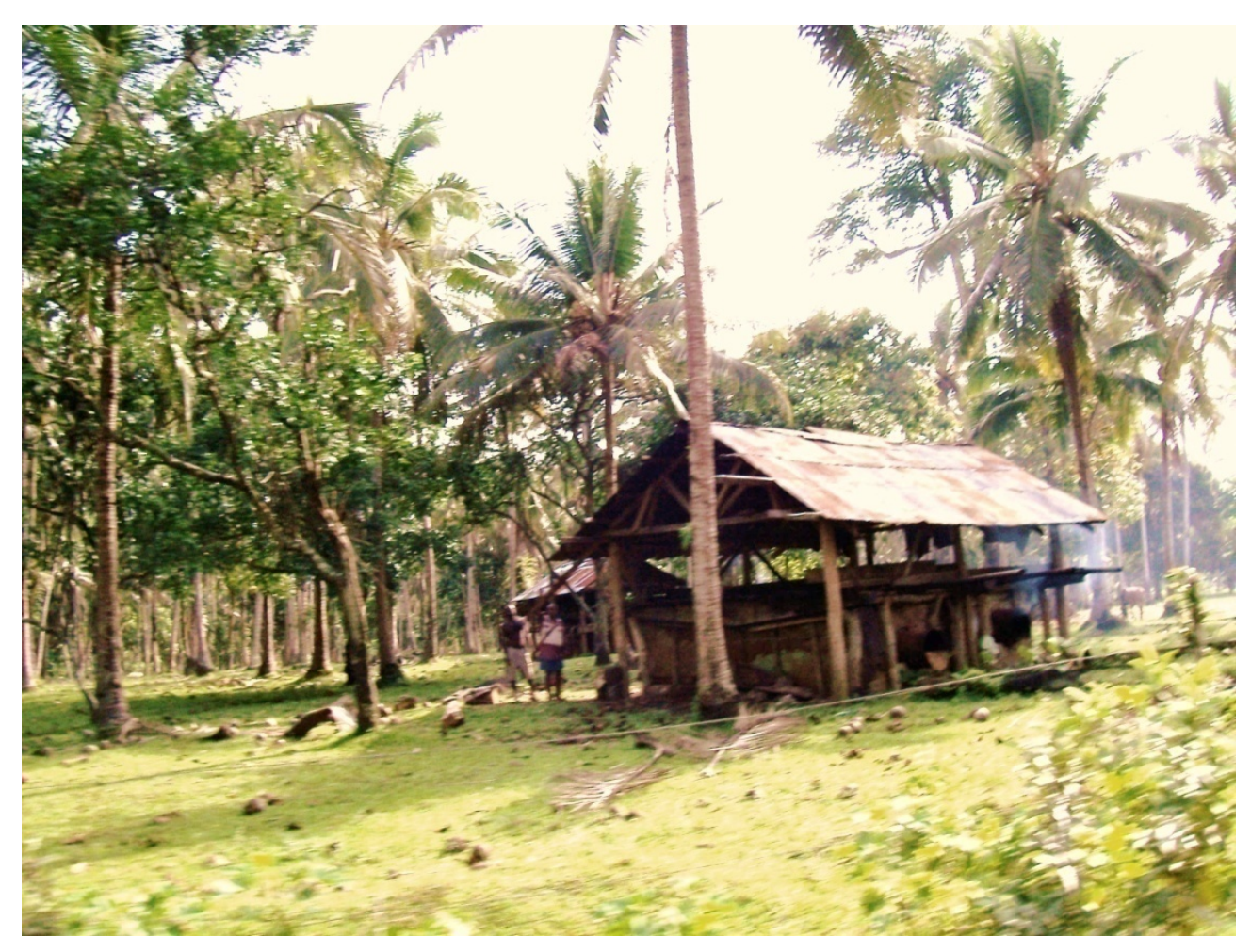

The elongated spread - North-North-West to South-South-East - of the Vanuatu archipelago of islands gives rise to a great deal of diversity across the country. Whilst the significant majority of the population is Vanuatu born Melanesians, the culture and languages are dramatically different throughout the Vanuatu islands. The North-South spread of the islands also gives rise to a diversity of weather and climate.

\section{VANUATU CARBON CREDITS PROJECT}

The Vanuatu Carbon Credits Project (VCCP) was established in partnership between Victoria University of Wellington and the Government of Vanuatu in 2006. The overall objective of the VCCP is to stimulate climate change mitigation by building capacity for Vanuatu to gain access to carbon finance for climate-friendly forms of sustainable development. The project is being driven because of the many benefits of climate change mitigation in Vanuatu: 
- Forest conservation

- Biodiversity conservation

- Sustainable development for local Ni-Vanuatu communities

- Climate change mitigation

- Energy independence and security

- Improved international political respect

- Alternative development opportunities

- Sustainable income opportunities for rural communities

- Publishing and presenting policy implications of experience in Vanuatu, especially Kyoto Protocol and UNFCCC such as the development of Reducing Emissions from Deforestation and Degradation (REDD)

- Marketing opportunity for tourism and export products

The VCCP is led by the Vanuatu NACCC, with the support of an international team of experts. The international team is led by Dr. Sean Weaver, whose principal research interest is the development of REDD policy that works on at a grassroots level. Figure 4 shows part of the international team (Tim Hewitt, Murray Ward, Sean Weaver and Martin Herold from left to right) at the UNFCCC COP13/MOP3. 


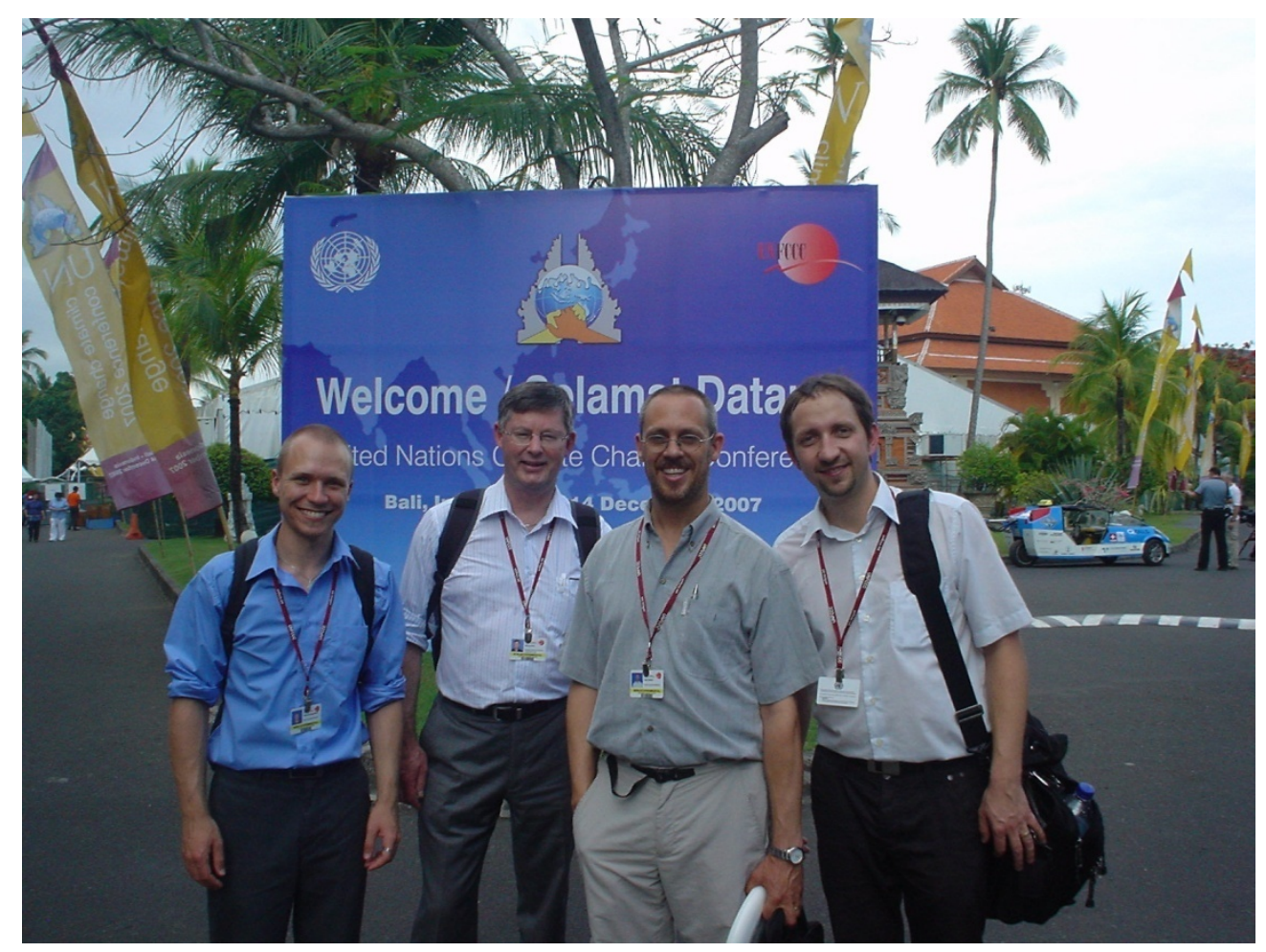

(Photo sourced from Herold, 2007)

Following the capacity building of the VCCP in Vanuatu and in recognition of the priorities of the Vanuatu Government the NACCC has identified a number of work programmes to carry out over the coming years in regards to forestry and renewable energy. One of these is to explore the possibility of a biodiesel pilot project. 
The NPV model used in this study is useful as a tool to determine the economic feasibility of a fuel swap, which also largely determines whether the fuel swap would be eligible for funding via the CDM. The Vanuatu fuel swap economic model shows that it is very likely that an investor or entrepreneur would consider that the fuel swap project would not be feasible, unless additional finance was available to recognise the benefits of the project that may not traditionally be valued in the economy. This is a very useful outcome as it shows that the project would be additional under the rules of the CDM, and that the project is worth further investigation and a level of commitment from the Government of Vanuatu, investors, CDM project developers, and entrepreneurs. It must be emphasised that this model is a best estimate using data currently available, and so is likely to be similar to investors' predictions. This means that the model does have limitations, for two main reasons: unpredictability of future price trends and lack of quality data. This biodiesel economic feasibility section of the study gives the financial results for each of the components that are considered relevant to the economic feasibility - such as the price of coconut oil and the discount factor - followed by the results of the overall model. The first of the financial components considered is the initial capital investment required to construct a biodiesel plant.

\section{BIODIESEL PRODUCTION PLANT CAPITAL INVESTMENT}

As shown in the literature review, there are few published economic analyses on biodiesel plants and many of these do not use direct plant capital costs. The one article found that gives a relevant figure is van Kasteren and Nisworo (2007). Van Kasteren and Nisworo (2007) estimate the plant construction cost to be US\$1,997,721 for a biodiesel plant using waste cooking oil and methanol, with a production capacity of 8,000 tonnes per year. Given that the model in this research is for a ten million litre per annum plant equivalent to 8,800 tonnes per annum - the figure used by van Kasteren and Nisworo 
(2007) is a good estimate for this research. Another source of information on plant costs is Clements et al. (2006), which shows a graph of plant capacity versus installed plant cost for various qualities of feedstock. For coconut oil, assuming a free fatty acid level of close to $10 \%$, a plant with capacity of ten million litres per annum, is estimated to have an installed cost of approximately 4.8 million USD. Because both of the estimates for installed capital cost have legitimate, but different, methods, the Vanuatu model uses a mean of the two figures. The mean is approximately 3.4 million USD. However, this figure is an estimate of plant cost for developed countries, so this model assumes an added cost of ten percent from inefficiencies experienced in Vanuatu. Adding ten percent gives a final estimation of plant cost of 3.7 million USD.

To complete a full financial feasibility study of this project requires combining the capital start-up cost with a collection of the best available data on the operating costs and revenue of the plant. In particular, this study includes detailed research of the available estimates of future prices of CERs, coconut oil, and fossil diesel.

\section{CER PRICE}

The price of CERs is required for the economic feasibility analysis because it will be used to calculate the contribution of the potential CDM financing to the profitability of the fuel swap. The most up-to-date and comprehensive carbon pricing data is collected by IDEAcarbon with monthly surveys. Carbonpositive publishes a monthly analysis of the IDEAcarbon survey on their website www.carbonpositive.com. Carbonpositive (2008) gives a range of CER prices, which are dependent on the contractual arrangement between the CDM project developer or host country DNA and the CER buyer. The three most important aspects of the contract are the vintage of the CERs, the distribution of risk, and the timing of the payment. The vintage of the CERs is the year or years in which the CERs are expected to be generated from the CDM project. The secondary market CER price is quite consistent across CP1, ranging from a low of $€ 15.30$ for December 2009 delivery to a high of $€ 15.80$ for December 2012 delivery. The price for delivery beyond 2012 is not given by carbonpositive and is relatively unknown because of the lack of decision and commitment on rules and level of emission cuts for the second commitment period (CP2). The distribution of risk in a contract between the buyer and seller in the 
CER market refers to whether the buyer or seller is liable for the failure of the project to deliver the agreed amount of CERs. As of March 2008 a precedent for litigation over CER seller failure of delivery has not yet been established. Being an international legal dispute, it is likely that the case would revert to the legal principles of the United Kingdom (UK). The UK legal principles would likely result in the requirement of the replacement of the loss with an equivalence of CERs bought in the international market or money to the value to the CERs. This would be the likely result of a contract in which the seller took on full risk of delivery failure. However, it is also possible for the buyer to enter a contract in which they take on the risk of any or all possible situations of failure of delivery. The risk is usually divided into the risks of the project getting through to official CDM status including methodology, validation, and registration, as well as the volume risk. The volume risk is the risk that the project may underperform and generate fewer CERs than was estimated in the project idea note (PIN) or project design document (PDD). The final difference is that of the timing of payment, which can be upfront to finance the development of the project (forward selling) or payment on delivery of the CERs. The contract can also specify a proportional combination of upfront payment and payment on delivery.

For the Vanuatu fuel swap model the following assumptions were made:

- The seller will take on the risks through to registration, and the buyer will take on the risks of volume

- The buyer will make payment on CER delivery

- The CER price will be similar for post-2012 vintages

The assumptions made about the contract are not a prediction of what will happen, nor a normative statement of what should happen; the contractual assumptions are just one possibility among a range of possibilities available to a buyer and seller. The payment timing at delivery is common practice and simple, but would require either more equity or debt financing in the initial stages of the project. It is possible that the post-2012 CER price could be similar to the current price, however it could be lower, higher, or even non-existent depending on the international climate change policy negotiations leading up to and including the COP-15 in Copenhagen in December 2009. Whilst the current forward price is the best available predictor of future prices, it is a poor estimation with 
great market uncertainty. Investor risk due to uncertain CER prices is another cause of higher discount rates for economic feasibility analysis.

Given the assumptions listed above, the most appropriate price assumption for CERs for the Vanuatu fuel swap model is $€ 11$ per CER, which is the mean price given by carbonpositive (2008) for the assumed situation based on the March 2008 survey by IDEAcarbon. Given the March 2008 USA/EU exchange rate - derived from the Reserve Bank of New Zealand (2008) - of 1.551 USD per Euro, the CER price used in the Vanuatu fuel swap model is 17.06 USD.

While the CDM could be a source of ongoing revenue for the project, a significant ongoing cost of the fuel swap would be the cost of purchasing copra for processing.

\section{COCONUT OIL PRICE PROJECTION}

To simplify the model the model uses easily available coconut oil price projections as a cost rather than trying to estimate the cost of copra plus the cost of milling the copra into oil. This implicitly assumes that the cost of processing copra into oil would be the same as the average global copra processing cost.

The model assumes that the price of coconut oil in Vanuatu is equal to the world price for coconut oil because coconut oil is an internationally traded commodity and Vanuatu currently has the infrastructure to export coconut oil. The agricultural commodities market is typically very volatile, with significant swings often not predicted until very shortly beforehand. In line with this, very few long term projections are made regarding agricultural commodities. There are no long term price projections in academic journal articles from either the ScienceDirect or Web of Knowledge databases. However, the World Bank does produce long term projections of several agricultural commodities including coconut oil.

To complete the data set for the model, two assumptions were made. The first is that the rate of change in price between fixed points will be constant. To calculate the intervening prices on this basis, the assumed price at the fixed point is multiplied by the mean annual rate of change to the power of the number of intervening years. The mean annual rate of change is calculated using Equation 3. 


$$
1+R=\sqrt[n]{\frac{P_{t+n}}{P_{t}}}
$$

Where: $\quad R$ is the mean annual rate of change;

$n$ is the number of years between the World Bank projected price and the unknown price; and

$P_{t}$ is a World Bank projected price at year $t$.

To extend the projection beyond the year 2020, an annual rate of price inflation of $2.3 \%$ was applied. The long term inflation projection from the World Bank is $2.3 \%$, which is also used by the IEA (International Energy Agency 2007b; World Bank 2007). It is useful to note that although the accuracy of the nominal price projection is likely to be less for later years, the importance of the later years is also less in the model because of the use of a discount rate.

\section{DISCOUNT RATE}

Discount rates are used in financial analysis to cover three issues: the time preference of money; inflation; and investment risk. In the context of this thesis the time preference of money and inflation can be taken from common global data as they are common across the market. Any local difference in the rate of inflation will be largely offset by the USA currency basis because changes in the rate of inflation in Vanuatu would be neutralized in the international market via the correction of the exchange rate. The level of risk, however, is particular to the fuel swap project. This study uses an estimated weighted average cost of capital (WACC) discount rate estimated using the capital asset pricing model (CAPM). The discount rates used in NPV project analysis are typically the WACC of the firm, or the WACC derived from the CAPM. The WACC is very easy to calculate for a firm that is considering undertaking further projects that are similar to the firm's current operations because if the risk profile of the project is similar to that of the firm, the firm's current WACC can be used. However, for the Vanuatu fuel swap model a 
separate firm in very similar circumstances - particularly in regards to risk - would need to be analysed in order to choose an appropriate estimate of WACC.

Using the CAPM one can split the risk from different sources because of the additive property of CAPM $\beta$ s. The Vanuatu fuel swap model splits the $\beta$ into country risk and business type risk, and systemic components. The more detail that the risk is divided into, the more accurate the estimated discount rate will be. In particular, it would be very difficult to find a business that was similar to the Vanuatu fuel swap project in terms of both location as well as activity type.

It is preferable to estimate an adjusted WACC based on the levered cost of equity to take into account the effect of a project's financing mix due to the tax shield. In the case of the Vanuatu fuel swap the unlevered and levered costs of capital can be assumed to be equivalent because there is no tax shield in Vanuatu, which has no company tax.

Vanuatu has no public share market, so the country specific equity risk premium cannot be calculated. The Pacific region does have a public share market, the South Pacific Stock Exchange (SPSE), which is monitored by the Kontiki South Pacific Stock Exchange Index (KSPX). However, the KSPX is not a useful indicator because of the small data sample; in March 2008 the KSPX had only sixteen stocks listed, and the SPSE has only been operating region-wide since 2000 . The most appropriate equity risk premium to be used in the Vanuatu fuel swap model is the equity risk premium for emerging markets. According to Grootveld and Salomons (2003) the average equity risk premium for emerging markets - from 1985 to 2001 - was 3.1\% when weighted by market capitalisation and $12.7 \%$ on an equal weighted basis. The difference between the two methods of data-weighting show that the larger economies have a much lower equity risk premium. The Vanuatu fuel swap model developed in this study uses the equally weighted equity risk premium because the market capitalisation weighted average is biased towards large economies, while Vanuatu is a very small economy. The equity market premium is calculated as a USD denomination.

The Vanuatu fuel swap model of this study uses twenty year US Treasury constant maturity securities as an indicator for the risk-free return because the twenty year period covers the lifespan of the proposed project and US Treasury bonds are typically 
used as risk-free rate of return indicators by finance institutions and researchers. The USA interest rate of the US Treasury twenty year constant maturity is $4.30 \%$ per annum in nominal terms (United States of America Federal Reserve 2008).

The unlevered equity beta of the project is estimated for the Vanuatu fuel swap model by taking a published beta for a USA company with a similar profile to the project and translating it into an unlevered equity beta using Hamada's formula. Hamada's formula which is largely based on the propositions of the CAPM and Modigliani and Miller - is commonly used in corporate finance for the purpose of toggling between levered and unlevered betas. The USA company that is used for the purpose of beta estimation is the Allegro Biodiesel Corporation, which is publicly listed on the USA Over the Counter Bulletin Board Exchange. The Allegro Biodiesel Corporation is a Louisiana based company that operates one medium sized biodiesel refinery. According to Reuters, the Allegro Biodiesel Corporation has a beta value of 2.03 (Reuters 2008). This means that the stock is substantially more volatile than the USA share market, represented by the Standard and Poors 500 index. The Reuters information also shows that the Allegro Biodiesel Corporation has a debt to equity ratio of 1.53 (Reuters 2008). To estimate a beta for the Vanuatu fuel swap project, it is necessary to eliminate the tax shield effect from the beta of the Allegro Biodiesel Corporation. The USA corporate tax rate for 2007 was forty percent (KPMG 2007). Equation 4 is known as Hamada's formula and gives the relationship between the levered equity beta, $\beta_{\mathrm{E}}$, and the unlevered equity beta, $\beta_{\mathrm{A}}$.

EQUATION 4: HAMADA'S FORMULA: ADAPTED FROM HAMADA (1972)

$$
\beta_{E}=\beta_{A}\left[1+\left(1-T_{C}\right) \frac{B}{S}\right]
$$

Where: $\quad \mathrm{T}_{\mathrm{C}}$ is the corporate tax rate;

$\mathrm{B}$ is the amount of debt;

$\mathrm{S}$ is the amount of equity;

$\beta_{\mathrm{E}}$ is the levered equity beta; and

$\beta_{\mathrm{A}}$ is the unlevered equity beta. 


$$
\begin{gathered}
\beta_{A}=\frac{\beta_{E}}{1+\left(1-T_{C}\right) \frac{B}{S}} \\
\beta_{A}=\frac{2.03}{1+(1-0.4) 1.53} \\
\beta_{A}=1.06
\end{gathered}
$$

As discussed above, the CAPM - as represented in Equation 6 - describes the relationship between a project's risk, the expected risk-free rate of return, the expected rate of return of the market, and the expected return of the project. The expected return on the project is equal to the estimated risk premium plus the expected risk-free rate of return.

EQUATION 6: CAPITAL ASSET PRICING MODEL

$$
E\left(R_{A}\right)=R_{F}+\left[E\left(R_{M}\right)-R_{F}\right] \beta_{A}
$$

Where: $\quad E\left(R_{A}\right)$ is the expected return on the project;

$\mathrm{R}_{\mathrm{F}}$ is the risk-free rate of return;

$\mathrm{E}\left(\mathrm{R}_{\mathrm{M}}\right)$ is the expected rate of return in the market; and

$\beta_{\mathrm{A}}$ is the project beta.

EQUATION 7: CAPITAL ASSEST PRICING MODEL - SUBSTITUTION OF DATA

$$
E\left(R_{A}\right)=0.043+[0.127] 1.06=0.178
$$

The Vanuatu fuel swap model uses nominal price data, and so also uses a nominal discount rate to calculate the net present value. The nominal discount rate used is $17.8 \%$. The net present value model used in this study will apply the discount rate to all projected costs and revenue of the fuel swap, including the revenue from biodiesel sales.

FOSSIL FUEL PRICE PROJECTION

Because biodiesel is a direct substitute for fossil diesel, it is assumed that biodiesel will be purchased rather than fossil diesel whenever it is cheaper. Therefore, fossil fuel price projections are used in this study as a proxy for biodiesel prices. The price of fossil 
diesel has been very volatile due to a wide range of economic drivers combined with asymmetrical knowledge about supply capacity. There is much debate regarding future crude oil supply and current reserves, particularly with uncertainty in the Middle East. An example of the divergence in view is authors Duncan Clarke and David Strahan. Duncan Clarke calls peak oil a myth, while David Strahan raises the question of whether global warming is even a problem given the imminence of peak oil (Clarke 2007; Strahan 2007). However, the importance of oil to the world economy means that several institutions project oil prices, based on the work of a large number of experts. This study uses crude oil price projections from the International Energy Agency (IEA) because it is the only large reputable institution that publishes a time series projection that is suitable for the Vanuatu fuel swap model. The IEA time series extends out to 2030, which is after the end of the life of the biodiesel production plant. The crude oil price projections are given in Table 3 in nominal USD, calculated by assuming a constant rate of change between projections and an inflation rate of $2.3 \%$ per annum.

The price of crude oil has gone well above 100 USD in 2008, suggesting that the IEA projections may be too conservative. However, some of this significant change is offset by the lower value of the USA currency.

In order to translate these figures into a useful time series for the Vanuatu fuel swap model, two assumptions are made. Firstly, it is assumed that the relationship between the price of crude oil and fossil diesel is constant over time. Therefore, a conversion factor for converting the price of crude oil to the price of fossil diesel can be calculated from the prices in 2006. Secondly, as in the coconut oil price dataset, it is assumed that the annual mean rate of change of price is constant over the years between those projected by the IEA. As such, Equation 8 is used to calculate the mean annual rate of change.

EQUATION 8: MEAN ANNUAL RATE OF CHANGE

$$
1+R=\sqrt[n]{\frac{P_{t+n}}{P_{t}}}
$$


Where: $R$ is the mean annual rate of change;

$n$ is the number of years between the IEA projected price and the unknown price; and

$P_{t}$ is an IEA projected price.

The price of fossil diesel in Vanuatu is taken as the average of the prices given in interviews: 91, 85, and 92.5 vatu per litre; at an exchange rate of 0.00827 USD per Vatu, these give a price of 0.79 USD per litre of fossil diesel. The resulting fossil diesel price projection is given in Table 3 . 
TABLE 3: NOMINAL PRICE PROJECTION OF CRUDE OIL AND FOSSIL DIESEL (ADAPTED FROM INTERNATIONAL ENERGY AGENCY 2007B)

\begin{tabular}{|c|c|c|}
\hline Year & $\begin{array}{c}\text { Crude oil price } \\
\text { USD per bbl. }\end{array}$ & $\begin{array}{c}\text { Fossil diesel price } \\
\text { USD per litre }\end{array}$ \\
\hline 2007 & 62.4 & 0.871 \\
\hline 2008 & 63.2 & 0.881 \\
\hline 2009 & 63.9 & 0.891 \\
\hline 2010 & 64.7 & 0.901 \\
\hline 2011 & 65.7 & 0.917 \\
\hline 2012 & 66.9 & 0.932 \\
\hline 2013 & 68.0 & 0.948 \\
\hline 2014 & 69.1 & 0.964 \\
\hline 2015 & 70.3 & 0.980 \\
\hline 2016 & 72.3 & 1.008 \\
\hline 2017 & 74.4 & 1.037 \\
\hline 2018 & 76.5 & 1.066 \\
\hline 2019 & 78.6 & 1.097 \\
\hline 2020 & 80.9 & 1.128 \\
\hline 2021 & 83.2 & 1.160 \\
\hline 2022 & 85.5 & 1.193 \\
\hline 2023 & 88.0 & 1.226 \\
\hline 2024 & 90.5 & 1.261 \\
\hline 2025 & 93.0 & 1.297 \\
\hline 2026 & 95.7 & 1.334 \\
\hline 2027 & 98.4 & 1.372 \\
\hline 2028 & 101.2 & 1.411 \\
\hline 2029 & 104.1 & 1.451 \\
\hline 2030 & 107.0 & 1.492 \\
\hline
\end{tabular}

GREENHOUSE GAS ABATEMENT RATE

The rate of greenhouse gas abatement from the replacement of fossil diesel with coconut oil based biodiesel used in the model developed in this study is $2.65 \mathrm{~kg}$ of $\mathrm{CO}_{2}$-e per litre of biodiesel. This is based on the analysis carried out in the carbon finance section of this 
thesis, which uses the CDM methodology AMSI.D. - which is available online on www.unfccc.ch with all methodologies - as a basis for estimating the abatement rate. The abatement rate is used in the model to estimate the number of CERs that could be generated through the project and thus the revenue available to the project via the CDM by selling the CERs to a country that would otherwise fail to meet its international obligations under the Kyoto Protocol.

\section{METHANOL PRICE PROJECTION}

The study requires the price projection of methanol because methanol is a key input in the transesterification process of biodiesel production. Most of the methanol produced worldwide is produced from natural gas. Therefore, the price of methanol is assumed to be very closely correlated to the price of natural gas. A correlation factor between the international price of methanol and the international price of natural gas was calculated by comparing the average 2006 prices of natural gas and methanol. There is no published methanol price projection series, so a gas price projection series is used to estimate the change in methanol price. As with fossil fuel the IEA is the most reputable institution that publishes a long term natural gas price projection so the natural gas projection from the International Energy Agency (2007b) was treated the same as for the crude oil time series by assuming a constant rate of change over intervening periods. The historical methanol price used to calculate the correlation factor between methanol and natural gas was sourced from Methanex (2008). The projected price of natural gas in USD per million British Thermal Units (MBtu) and methanol in USD per tonne is shown in Table 4. 
TABLE 4: PROJECTED PRICE OF NATURAL GAS AND METHANOL (SOURCE: IEA (2007B) AND AUTHORS OWN CALCULATIONS)

\begin{tabular}{|c|c|c|}
\hline Year & $\begin{array}{l}\text { Natural Gas } \\
\text { USD per MBtu }\end{array}$ & $\begin{array}{l}\text { Methanol } \\
\text { USD per tonne }\end{array}$ \\
\hline 2007 & 7.37 & 433 \\
\hline 2008 & 7.47 & 393 \\
\hline 2009 & 7.58 & 399 \\
\hline 2010 & 7.69 & 404 \\
\hline 2011 & 7.87 & 414 \\
\hline 2012 & 8.05 & 424 \\
\hline 2013 & 8.24 & 433 \\
\hline 2014 & 8.43 & 444 \\
\hline 2015 & 8.63 & 454 \\
\hline 2016 & 8.88 & 467 \\
\hline 2017 & 9.13 & 480 \\
\hline 2018 & 9.39 & 494 \\
\hline 2019 & 9.66 & 508 \\
\hline 2020 & 9.94 & 523 \\
\hline 2021 & 10.23 & 538 \\
\hline 2022 & 10.52 & 553 \\
\hline 2023 & 10.82 & 569 \\
\hline 2024 & 11.13 & 585 \\
\hline 2025 & 11.45 & 602 \\
\hline 2026 & 11.78 & 619 \\
\hline 2027 & 12.12 & 637 \\
\hline 2028 & 12.46 & 656 \\
\hline 2029 & 12.82 & 674 \\
\hline 2030 & 13.19 & 694 \\
\hline
\end{tabular}

Like the other incomplete price projections, a constant rate of change is assumed between projections; thus intervening periods are estimated using the same method as with coconut oil and fossil diesel price projections. 
The net calorific value (NCV) of fossil diesel and the NCV of the proposed biodiesel are measurements of the energy content of the fuels. The NCVs are required so that the fuels can be compared - in terms of both cost and GHG emissions - on an equivalent energy basis. Where the absolute net calorific value of fossil diesel is being used in isolation, the value of 43.33TJ/t from the revised 1996 IPCC Guidelines for Greenhouse Gas Accounting (Intergovernmental Panel on Climate Change 2006) is used. However, when the net calorific values of fossil diesel and biodiesel are being compared in order to estimate a rate of displacement, the values of $42 \mathrm{TJ} / \mathrm{t}$ for fossil diesel and $38 \mathrm{TJ} / \mathrm{t}$ for biodiesel from Caluba et al. (2004) are used because the accurate determination of the consistency between figures is more important than the absolute value. Biodiesel has been shown to perform better than fossil diesel relative to its NCV because of the engine efficiency gained by the higher lubricity of biodiesel. However, this factor has not yet been adopted by the CDM EB.

\section{OPERATING COSTS}

There is a large range of comprehensiveness in the operating cost data used in the economic feasibility literature covered in the literature search section of this thesis. Many of the peer reviewed articles omitted significant categories of cost such as the catalyst in the van Kasteren and Nisworo (2007) article. Due to the lack of clear data from academic journals, the Vanuatu model takes the mean of two sets of clear and transparent data, which originate from biodiesel experiences in the USA. The accuracy of the model would be improved with information on operating costs in Vanuatu; however, the difference would not be significant as the operating costs as estimated over the fifteen years of production account for only $12 \%$ of the total production cost. The two sources are Clements et al. (2006) and Fortenbery (2005) and are compared in Table 5. 


\begin{tabular}{lll}
\hline & Clements et al. (2006) & Fortenbery (2005) \\
\hline Chemicals & 0.03 & 0.0085 \\
Labour & 0.026 & 0.042 \\
Utilities & 0.007 & 0.015 \\
Other & 0.015 & 0.015 \\
\hline TOTAL & $\mathbf{0 . 0 7 8}$ & $\mathbf{0 . 0 8 0 5}$ \\
\hline
\end{tabular}

\section{MODEL UNCERTAINTY}

This model has limitations, for two main reasons. The two main reasons are the unpredictability of future prices, and the lack of quality data. The model assumes a geographically consistent global price of internationally traded commodities. This means that the most influential pricing data - coconut oil, methanol, fossil diesel - can be quality data sourced from well respected global institutions. No matter how well respected the global institutions are, they cannot perfectly predict future economic and financial data. This is the largest element of uncertainty in the model because of the volatility of the price of fossil fuels as well as vegetable oil. In particular, the fossil diesel price is based upon the latest crude oil price projections from the IEA. The projections include a projection of the price of crude oil rising from around 62 USD per barrel (bbl) in 2006 to almost $65 \mathrm{USD} / \mathrm{bbl}$ in 2010. Since this projection was made, the actual price of oil has reached well over $100 \mathrm{USD} / \mathrm{bbl}$ in the first quarter of 2008. An upward shift in the price of fossil diesel would have a significant effect on the model, resulting in a much more promising financial situation for the project. The general volatility of fossil fuel price due to supply constraints and strong demand growth also affects the price of methanol, which is primarily produced from natural gas. The volatility of the vegetable oil market raises uncertainty in the model in multiple ways. On the one hand an increase or decrease in the global price of coconut oil simply increases or decreases the cost of production thus affecting the project's profitability. On the other hand, a significant reduction in the global price of coconut oil could dramatically change the context of the project if domestic copra supply dropped below that required for the plant. This would mean that the plant would need to import coconut oil, which would eliminate some of 
the qualitative and subjective supporting arguments for the project around the topic of sustainable development and climate change mitigation.

\section{MODEL RESULTS}

The Vanuatu fuel swap model shows that the estimated net present value of the project without carbon finance support is a loss of approximately 1.7 million USD. This means that the project is financially unattractive to investors in a business as usual scenario. However, the inclusion of revenue from CER's generated via the CDM would give an estimated positive net present value of approximately 1.1 million USD. This shows that with the aid of carbon finance the Vanuatu fuel swap project is financially viable and worth pursuing further. These results are shown in Table 6. 
TABLE 6: FINANCIAL ANALYSIS RESULTS (THOUSANDS OF USD)

\begin{tabular}{|c|c|c|c|c|c|c|c|c|c|c|c|c|c|c|}
\hline \multirow[b]{2}{*}{ Year } & \multicolumn{8}{|c|}{ Costs } & \multicolumn{2}{|c|}{ Revenue } & \multicolumn{2}{|c|}{ Nominal Profit } & \multicolumn{2}{|c|}{ Discounted Profit } \\
\hline & Construction & Coconut oil & Methanol & Chemicals & Energy & Labour & Other & Total Cost & $\begin{array}{l}\text { Fuel } \\
\text { Sales }\end{array}$ & $\begin{array}{l}\text { CER } \\
\text { Value }\end{array}$ & $\mathrm{BAU}$ & CDM & $\mathrm{BAU}$ & CDM \\
\hline 2009 & 3,700 & 8,527 & 351 & 207 & 117 & 369 & 165 & 13,437 & 8,446 & 452 & $-4,991$ & $-4,539$ & $-4,991$ & $-4,539$ \\
\hline 2010 & 0 & 8,254 & 356 & 212 & 120 & 378 & 169 & 9,488 & 8,544 & 452 & -944 & -492 & -802 & -418 \\
\hline 2011 & 0 & 7,996 & 364 & 217 & 123 & 387 & 172 & 9,258 & 8,689 & 452 & -570 & -118 & -410 & -85 \\
\hline 2012 & 0 & 7,745 & 373 & 222 & 126 & 395 & 176 & 9,037 & 8,836 & 452 & -201 & 251 & -123 & 154 \\
\hline 2013 & 0 & 7,503 & 381 & 227 & 129 & 405 & 180 & 8,824 & 8,986 & 473 & 161 & 634 & 84 & 329 \\
\hline 2014 & 0 & 7,268 & 390 & 232 & 132 & 414 & 185 & 8,620 & 9,138 & 484 & 518 & 1,002 & 228 & 442 \\
\hline 2015 & 0 & 7,040 & 399 & 237 & 135 & 423 & 189 & 8,423 & 9,292 & 495 & 869 & 1,364 & 325 & 511 \\
\hline 2016 & 0 & 6,754 & 411 & 243 & 138 & 433 & 193 & 8,171 & 9,556 & 493 & 1,385 & 1,878 & 440 & 597 \\
\hline 2017 & 0 & 6,479 & 423 & 248 & 141 & 443 & 198 & 7,931 & 9,828 & 504 & 1,896 & 2,400 & 511 & 647 \\
\hline 2018 & 0 & 6,215 & 435 & 254 & 144 & 453 & 202 & 7,704 & 10,107 & 516 & 2,403 & 2,919 & 550 & 668 \\
\hline 2019 & 0 & 5,963 & 447 & 260 & 147 & 464 & 207 & 7,487 & 10,393 & 528 & 2,906 & 3,434 & 565 & 667 \\
\hline 2020 & 0 & 5,720 & 460 & 266 & 151 & 474 & 212 & 7,282 & 10,689 & 540 & 3,406 & 3,946 & 562 & 651 \\
\hline 2021 & 0 & 5,852 & 473 & 272 & 154 & 485 & 216 & 7,453 & 10,992 & 552 & 3,539 & 4,092 & 496 & 573 \\
\hline 2022 & 0 & 5,986 & 487 & 278 & 158 & 496 & 221 & 7,627 & 11,304 & 565 & 3,677 & 4,242 & 437 & 504 \\
\hline 2023 & 0 & 6,124 & 501 & 285 & 161 & 508 & 226 & 7,805 & 11,625 & 578 & 3,820 & 4,398 & 386 & 444 \\
\hline TOTAL & 3,700 & 103,425 & 6,251 & 3,657 & 2,075 & 6,527 & 2,911 & 128,548 & 146,423 & 7,536 & 17,876 & 25,411 & $-1,742$ & 1,145 \\
\hline
\end{tabular}


The inclusion of carbon finance revenue results in a nominal internal rate of return (IRR) of $20.6 \%$, which exceeds the nominal $17.8 \%$ return required to attract investment. Without the revenue from CERs the IRR is projected to be $13.9 \%$. The IRR was calculated using the Microsoft Excel 2007 IRR function. The most significant projected data sets by far are the price projections of coconut oil and fossil diesel. However, the model projects the Vanuatu fuel swap project to be annually profitable from its fourth year of operation onwards. Upfront financing from equity or debt is required to cover the construction cost of the refinery and losses over the first three years. From the fourth year onwards the project is increasingly profitable as the export price of coconut oil is projected to decrease while the import price of fossil diesel is projected to continually increase. By the final year of production the refinery is projected to make a nominal profit of approximately 4.4 million USD per year. However, that final year's profit has a present value of only 0.4 million USD because of the discount rate used for the relatively risky industry in an emerging economy.

\section{CARBON FINANCE OPPORTUNITIES}

The replacement of fossil diesel with renewable energy is very beneficial to the users as well as internationally. These benefits result in a number of support incentives being available to developers of renewable energy. The Vanuatu fuel swap is eligible to apply for several of these incentives to support the development of a large scale domestic biodiesel industry. One major source of finance for climate change mitigation is the carbon credit market. The Vanuatu fuel swap project would be eligible to apply for finance via the carbon credit market - either the compliance or voluntary market because it is a non-Annex I country within the Kyoto Protocol. This study formally assesses the project's eligibility for funding from the compliance market, via the CDM. The option of pursuing a transaction through the voluntary carbon market would need to arise from a separate analysis using parameters specific to that market, principally focusing on prices from the generation and sale of voluntary carbon units.

There are also a number of non-market sources of funding for the Vanuatu fuel swap. The project could apply for funding (e.g. to cover project development or transaction costs) from public or private sector grant sources such as the Australian government aid 
program (AusAID) or funding organisations that are specifically aiming to increase the uptake of renewable energy such as the Renewable Energy and Energy Efficiency Partnership (REEEP). This research shows that the Vanuatu fuel swap project is very likely eligible for funding support from all these sources, thereby demonstrating that the Vanuatu fuel swap is both technically and economically feasible in principle.

\section{CDM PDD}

The CDM project design document (PDD) is the document that a CDM project participant must submit to the UNFCCC in order for the project to be registered and validated (Ministry of the Environment, Japan 2007). The PDD is therefore the key document that the CDM EB uses to decide whether or not a project is eligible for the generation of CERs. The PDD has four main parts to it:

- Description of the proposed project and basic information (such as contact details);

- Choice, description, and justification of a baseline and monitoring methodology;

- Description and justification of additionality; and

- Environmental and stakeholder assessment.

The stakeholder interviews carried out for the purpose of this study were resoundingly positive towards the project and so this study focuses on whether it is feasible that a project developer could successfully complete the baseline and monitoring methodology and additionality sections of the PDD. Both of these components of the PDD are shown to be feasible in the following two sections of this study.

\section{CDM BASELINE AND MONITORING METHODOLOGY}

It is likely that the proposed Vanuatu biodiesel project could meet all of the eligibility requirements of the CDM small scale methodology called "grid connected renewable electricity generation" (AMS-I.D.) (United Nations Framework Convention on Climate Change Clean Development Mechanism Methodology Panel 2007d). For a CDM electricity generation project to be considered small scale it must have a total capacity of less than fifteen Megawatts (MW). The compliance costs of small scale projects are significantly reduced relative to large scale projects due to the simplified and streamlined process and a lower registration fee. The capacity of grid connected fossil 
diesel electricity generation on Efate Island is approximately 22MW, which is made up of two 4MW generators at Tagabe and 14MW from a variety of several smaller generators in the Port Vila central business district. The Tagabe generators are used to provide base load while the older, smaller, and less efficient generators in the Port Vila central business district are used to cover peak demand. In order to reduce compliance costs and use the small scale methodology the two locations - Tagabe and the Port Vila central business district - could be considered together within an overall Efate Island bundle of small scale projects if the Port Vila central business district location was limited to 7MW of biodiesel capacity within the 14MW facility. This would mean that CERs may not be able to be generated for the full biodiesel plant capacity of ten million litres.

Unelco would need to complete further investigation to estimate how much biodiesel would be used in the first $15 \mathrm{MW}$ of generation. The other option for using the baseline and monitoring methodology AMS-I.D. is for Tagabe and Port Vila to be registered as two separate CDM projects. This would increase compliance costs because each project would need to have full paperwork, registration, and verification. One strategic downside to using AMS-I.D. is that it only applies to renewable stationary electricity generation, and not to renewable transport fuels (United Nations Framework Convention on Climate Change Clean Development Mechanism Methodology Panel 2007d). This means any of the biodiesel plant's production that is diverted to transport in the future will not be eligible for CER generation under the project. Because the biodiesel production capacity will already exist at that hypothetical time in the future it would also be more difficult to prove additionality in order to register biodiesel for transport as a new CDM project. If the project was revised to involve biodiesel production for transport, then the project would be considered one single CDM project. This is because the size limit for non-electricity projects to be considered small-scale is a project that generates sixty thousand CERs per year. An up-side conservative theoretical maximum for ten million litres of transport biodiesel per year is twenty-seven thousand CERs per year, given the full maximum of $2.7 \mathrm{~kg} \mathrm{CO} 2$ per litre of diesel avoided. However, there is currently no approved small scale CDM methodology for transesterified biodiesel for transport. 
One option is to try to undertake a transport project using a similar existing methodology. One example is the 'plant oil production and use for transport applications' methodology (AMS-III.T). This methodology however is only for the production of pure plant oil - i.e. not transesterified - to be used as a blend of up to ten percent with diesel, or as a pure plant oil fuel. If the project involves the use of pure plant oil without blending with fossil diesel, the vehicles must be suitably modified to address the higher viscosity of straight vegetable oil compared to fossil diesel.

To develop a transesterified biodiesel production for transport project, the developer or DNA would need to initiate - and pay for - the development and approval of a new suitable small scale methodology. This option could potentially attract international grant finance due to the fact that any new methodology approved by the CDM Executive Board becomes an international public good, in which case the methodology design work would amount to an innovation for the international public good, and would enable a similar project type to be more easily undertaken in other developing countries.

To avoid having two separate CDM projects in order to cover the full volume of CERs available, Port Vila and Tagabe could be bundled together as one large scale CDM project. The large scale projects have higher compliance costs due to:

- Higher CDM registration fee

- More stringent methodology and project design documents that require more in-house or consultancy time

- Different designated operational entities (DOEs) must be contracted to carry out verification and certification

For a Vanuatu fuel swap project an additional and significant cost of registering as a large scale CDM project is that there is currently no appropriate large scale methodology. The generic approved renewable electricity generation methodology - AM0019 -- specifically excludes biomass, while the approved biomass-specific electricity generation methodology - AM0042 - is only applicable to biomass from "newly developed dedicated plantations". There is also a methodology - AM0047 - approved for production of biodiesel for fuel use, however, this methodology is only applicable to the production of biodiesel from waste plant oil or waste animal fat (United Nations Framework 
Convention on Climate Change Clean Development Mechanism Methodology Panel 2007b).

The most beneficial outcome for Vanuatu would be a coconut oil fuel swap project that combined electricity generation with transport fuels, given that the production of biodiesel through a transesterfication process would produce a fuel product that could be used for both purposes. As we have seen, such a project faces a number of policy challenges in relation to the CDM administrative process.

A project developer of a Vanuatu fuel swap would therefore have three broad options:

- Develop a new large scale CDM methodology;

- Wait for a new methodology to be approved without their input; or

- Develop a methodology for the voluntary carbon market.

Regarding the option of waiting, depending on when the Vanuatu fuel swap would commence, the methodology panel may have already altered AM0047 sufficiently for the new version of AM0047 to be suitable for the Vanuatu electricity generation fuel swap project. The CDM methodology panel has published a draft AM0047/Version 3, which includes the production of biodiesel from newly established dedicated crop plantations. In the methodology panel's summary recommendation to the EB on proposed new methodology number 233 (NM0233) they note that they are currently evaluating default emission factors for shift of pre-project activities, which would allow the inclusion of biomass sourced from a dedicated plantation that is not newly established (United Nations Framework Convention on Climate Change Clean Development Mechanism Methodology Panel 2007c).

A Vanuatu fuel swap project developer would need to weigh up the costs and benefits of the various choices of the project setup - electricity generation and/or transport - and of the baseline and monitoring methodology. These options as well as their main costs and benefits are summarized in Table 7. 
TABLE 7: COST AND BENEFITS OF THE TYPE OF BIODIESEL PROJECT

\begin{tabular}{|c|c|c|}
\hline Type & Benefits & Costs \\
\hline $\begin{array}{l}\text { Bundled Small } \\
\text { Scale CDM }\end{array}$ & $\begin{array}{l}\text { Lower transaction costs } \\
\text { than the other two CDM } \\
\text { options }\end{array}$ & $\begin{array}{l}\text { May not cover the entire } \\
10 \mathrm{~m} \text { litres of biodiesel }\end{array}$ \\
\hline $\begin{array}{l}\text { Two individual } \\
\text { Small Scale CDM } \\
\text { Projects }\end{array}$ & $\begin{array}{l}\text { Able to cover the full } \\
\text { volume of CERs }\end{array}$ & $\begin{array}{l}\text { Transaction costs } \\
\text { greater than for a single } \\
\text { project }\end{array}$ \\
\hline $\begin{array}{l}\text { Bundled Large } \\
\text { Scale CDM }\end{array}$ & $\begin{array}{l}\text { Able to cover the full } \\
\text { volume of CERs }\end{array}$ & $\begin{array}{l}\text { New methodology } \\
\text { would have to be } \\
\text { written and registered }\end{array}$ \\
\hline $\begin{array}{l}\text { Large scale } \\
\text { electricity and } \\
\text { transport Large } \\
\text { Scale CDM }\end{array}$ & $\begin{array}{l}\text { Recognition for fuel used in } \\
\text { transport assists transition } \\
\text { to low carbon transport } \\
\text { Supports a flexible energy } \\
\text { system }\end{array}$ & $\begin{array}{l}\text { New methodology } \\
\text { would need to be } \\
\text { written; the } \\
\text { methodology would be } \\
\text { substantially different to } \\
\text { others (upstream not } \\
\text { downstream) and thus } \\
\text { may not be accepted }\end{array}$ \\
\hline $\begin{array}{l}\text { Voluntary Carbon } \\
\text { Market }\end{array}$ & $\begin{array}{l}\text { Can include recognition of } \\
\text { co-benefits } \\
\text { Could include carbon } \\
\text { sequestration from } \\
\text { aforestation and soil carbon } \\
\text { Lower transaction costs } \\
\text { Could perhaps include } \\
\text { transport }\end{array}$ & $\begin{array}{l}\text { Generally lower value } \\
\text { than CERs }\end{array}$ \\
\hline
\end{tabular}

The analysis and justification of the additionality of the potential fuel swap project is the same regardless of the type of CDM Baseline and Monitoring, except that the level of detail and scrutiny can differ among the various voluntary carbon standards. 
For the proposed Vanuatu fuel swap project to be validated by a DOE and registered by the EB it must be considered additional. Additionality is required to ensure environmental integrity to the Kyoto Protocol by ensuring that the emission reductions from a project would not have happened without the existence of the CDM and the potential for the generation and sale of CERs. Whether the CDM project uses a large or small scale baseline and monitoring methodology, the additionality is proven in essentially the same way. For a project to prove additionality it must show that without CDM registration it will face credible and prohibitive barrier(s). The categories of barriers identified by the CDM EB are:

- Investment barrier

- Access-to-finance barrier

- Technological barrier

- Barrier due to prevailing practice

- Other barriers

For small-scale project activities these barriers are listed in Attachment A to Appendix B of Annex II of decision four of the Conference of the Parties to the UNFCCC serving as the first session of the Meeting of the Parties to the Kyoto Protocol. The Vanuatu fuel swap could be shown to be additional via all of the barrier categories except 'other'. This is based on two principal cross-cutting issues that relate to the various barriers. The first is the economic analysis shown in this study that demonstrates that without the prospect of generating CERs the project would not be sufficiently profitable to attract investment. The second issue is that a large scale biofuel project in the Pacific islands would be the first of its kind. Many of the benefits to Vanuatu that are explained in this research are also relevant to other Pacific Islands as well as other small island developing states around the world. Not one, however, has yet developed a large scale biofuel production facility. This is certainly a barrier due to prevailing practice.

There are a large number of benefits to the use of coconut oil for biodiesel production in the Pacific, but the Islands of the Pacific are struggling to develop a large scale biodiesel plant. There have been many discussions and workshops in various Pacific Islands 
regarding the development of a biodiesel industry including Fiji, Tonga, and Vanuatu. However, the impetus and momentum of the use of imported fossil diesel has not yet been shaken. Being the first large biodiesel project means that the Pacific region may lack the locally sourced labour and knowledge required to drive the project. It also means that a large scale biodiesel project will be considered to be more risky even though biodiesel plants are operating successfully elsewhere. This risk perception as well as the real risk created by the lack of local experience is sufficient to justify additionality on the basis of a technological barrier. This risk combined with the risk that is inherent in a small developing country means that it is difficult to access sufficient financing for the Vanuatu fuel swap project, one of the other categories of risk listed by the CDM EB. For example, Claire Dornic, Manager of CLA-CC, said that she was very keen to produce biodiesel from her copra crushing plant in Luganville, on the island of Santo. However, she did not have access to financial capital. She said that she would like to form a partnership in order to assist with both financial capital and technological knowledge. This is what the CDM is supposed to be all about.

All of these situations are also influenced by the economic context of the situation. John Chaniel, Chief Executive Officer (CEO) of Unelco Vanuatu, said that Unelco is a business representing shareholders, so final decisions come down to profitability. The economic analysis in this study shows that the proposed Vanuatu fuel swap would not be economically viable without support from carbon finance. This is a suitable demonstration of the investment barrier, which is commonly used as a strong additionality argument by CDM project applicants. For projects that produce revenue other than from the sale of CERs generated the CDM EB suggests that a CDM applicant either compares the investment of the project with another more carbon intensive project, or compares the investment to some type of financial benchmark. Both types of financial analysis can be done by either the calculation of an internal rate of revenue (IRR) or a net present value figure. Either way the project is unlikely to be undertaken if investors and entrepreneurs believe that investments will generate greater returns elsewhere. The net present value analysis carried out in this study clearly shows that the Vanuatu fuel swap is currently additional by way of the investment barrier. The Vanuatu fuel swap model would need to be updated in the future with the latest data and context available to be used to prove additionality. With the volatility of crude oil and coconut 
oil prices it is difficult to know whether the proposed Vanuatu fuel swap project would remain additional via the investment barrier in the future.

\section{ESTIMATION OF CER VOLUME AND VALUE}

The volume of CERs to be generated is estimated in the project design document (PDD), based on the selected baseline and monitoring methodology. Given the aim and level of rigour required by CDM methodologies, this study will assume that all of the possible methodologies will generate a very similar volume of CERs, as long as the full ten million litres of biodiesel is covered by the project boundary. Since the only appropriate methodology that has been approved by the CDM EB yet is AMS-I.D. this study uses AMSI.D. to estimate the volume of CERs to be generated over the fifteen year lifespan of the proposed project.

Simply speaking, all methodologies establish a business as usual baseline and subtract from this the CDM project activity emissions and leakage emissions to calculate the volume of CERs generated by the CDM project. The methodology AMS-I.D. requires that the baseline be calculated using default diesel generator emission factors where all electricity is generated from diesel or fuel oil, or for all other systems an emission factor for the electricity system must be calculated using either of the following two methods:

- Combined Margin (CM) method as described in the "Tool to calculate the emission factor for an electricity system'

- Weighted average emission factor of the current electricity generation mix in that system

For either of these two methods the latest data will need to be used, which could be 2008 or 2009 data. In 2007 the Port Vila grid electricity was generated from the following locations:

- Two 4MW diesel generators at Tagabe

- $14 \mathrm{MW}$ of diesel generation capacity in Port Vila central business district

- One 275kW test wind turbine at Devil's Point 
Over 2008 Unelco is intending to install ten wind turbines at Devil's Point, with a rated capacity of 275kW per turbine (Vergnet Groupe 2007; Vanuatu Daily Post 2008). The wind farm will have a total rated capacity of $2.75 \mathrm{MW}$. The baseline methodology will also need to carefully account for the volume of coconut oil that is currently used in Unelco's diesel generators as a mix with fossil diesel. Figure 5 shows the 4MW diesel generator running on a blend of fossil diesel and coconut oil.

\section{FIGURE 5: DIESEL GENERATOR AT TAGABE POWER PLANT}

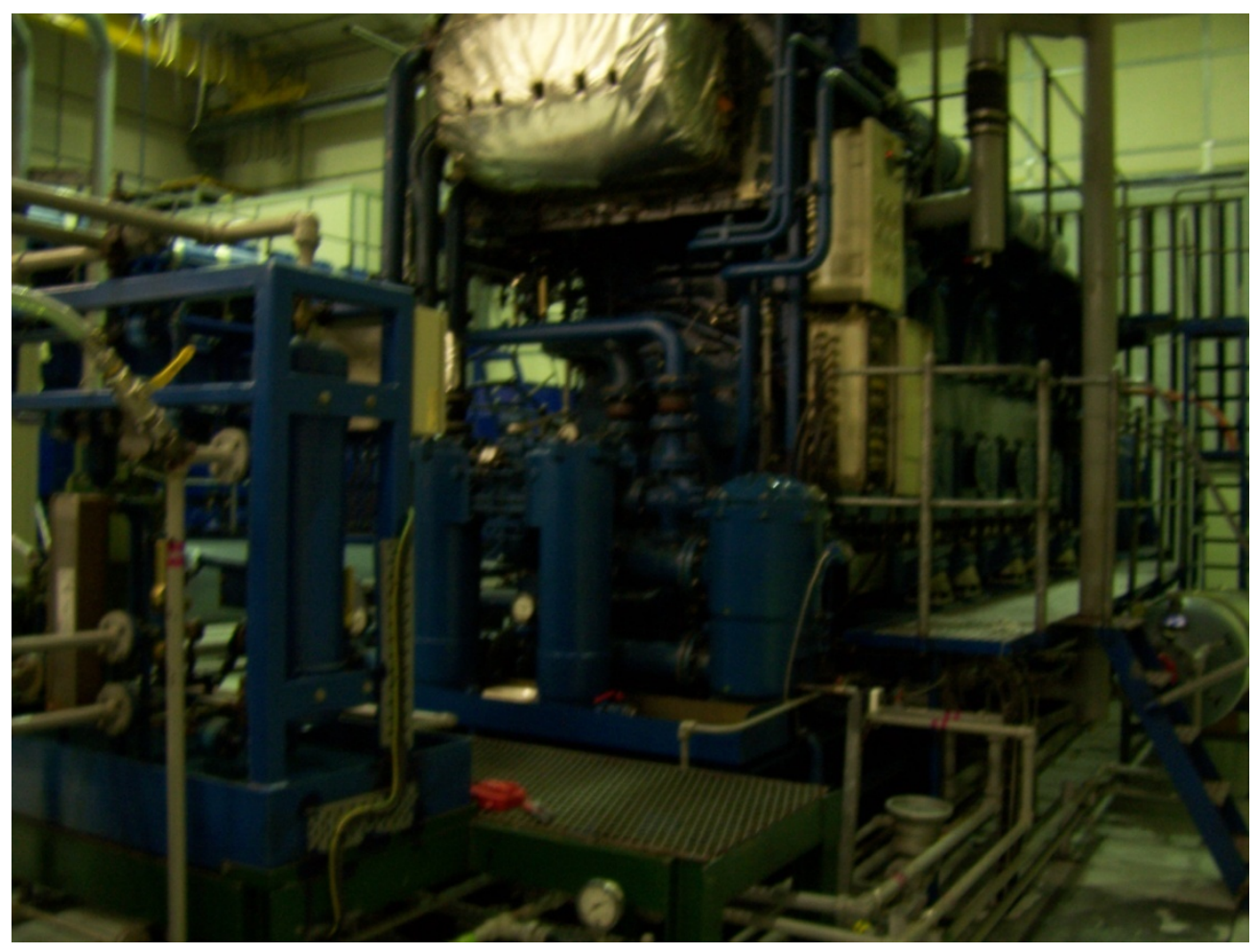

Unfortunately the methodologies available do not allow for a scenario in which the fossil diesel is replaced with biodiesel in priority to replacing the use of raw coconut oil. This scenario may be possible if the other diesel generators in the Port Vila central business district were to run on close to $100 \%$ biodiesel in order to use the full ten million litres of biodiesel produced per year on top of the current use of straight vegetable oil. Despite not taking the full potential scenario into account, the combined margin method for calculating the electrical grid's emission factor is used in this study because it is the most rigorous and reliable. 
The relevant electric power system is the entire grid of Efate Island, of Vanuatu, which covers the South-West quadrant of the island. The electric power system as defined here is the Efate grid in its entirety and thus the net electricity imports are not relevant, so a default emissions factor for imports of zero tonnes of $\mathrm{CO}_{2}$ per $\mathrm{MWh}$ can be used. The operating margin emissions factor is based on the emissions of only the power plants within the system that are not low-cost/must-run plants. Low-cost/must-run plants are those that typically have a low marginal cost of electricity production and so continue to produce electricity regardless of changes in demand, such as a run of the river hydro station. Within the Efate grid the Devil's Point windfarm is a low-cost/must-run plant, while the diesel generators at Tagabe and the Port Vila central business district are not. The CDM EB prefers applicants to calculate the Operating Margin (OM) by treating the power plants separately in terms of generation and fuel use, before aggregating together to calculate an emission factor. However, because of a lack of data, aggregated fuel use and generation figures were used in this study.

In $20029,818,000$ litres of diesel were used to generate 33,809 MWh of net electricity (Secretariat of the Pacific Regional Environment Programme 2004). This analysis assumes a constant efficiency of the diesel generation in order to estimate the data that would be used by a CDM business case developed for the Vanuatu fuel swap. The assumption is also made in line with those of the economic analysis that the project is planned for 2009. This means that the project development and CDM application would be carried out in 2008, likely using data from 2005-2007 as base data. In order to estimate the data over this time period, this study makes the assumption that the average electricity generation growth rate in Port Vila of 3.9\% from 1992 to 2002 (ibid.) will continue through to 2007. Although Unelco introduced the use of coconut oil at Tagabe gradually over 2006 and 2007, the data on quantities of coconut oil combusted is not publicly available. Therefore, the research makes a conservative estimate of a ten percent reduction in fuel use in 2007. It is also assumed that the test wind turbine achieved an average load rating of $25 \%$ over its seven months of operation in 2007. $351 \mathrm{MWh}$ of the electricity generation in 2007 is thus assumed to have been supplied by 
the wind turbine. These assumptions result in the data estimations for 2002-2007 given in Table 8.

TABLE 8: BASELINE DATA

\begin{tabular}{rrc}
\hline & Generation & Diesel \\
\hline & MWh & \multicolumn{1}{c}{ kL } \\
$\mathbf{2 0 0 2}$ & 33,809 & 9,818 \\
$\mathbf{2 0 0 3}$ & 35128 & 10201 \\
$\mathbf{2 0 0 4}$ & 36498 & 10599 \\
$\mathbf{2 0 0 5}$ & 37921 & 11012 \\
$\mathbf{2 0 0 6}$ & 39400 & 11441 \\
$\mathbf{2 0 0 7}$ & 40936 & 10699 \\
\hline
\end{tabular}

The OM can therefore be calculated as in Equation 9.

EQUATION 9: OPERATING MARGIN CALCULATION

$$
\begin{aligned}
\mathrm{EF}_{\text {grid }, \mathrm{OM}}= & \frac{(11012.09+11441.56+10699) \times\left(43.33 \times 20.2 \times 0.99 \times \frac{44}{12} \times 10^{-3}\right)}{(37920.93+39399.85+40936.44)} \\
& =0.891 \mathrm{tCO}_{2} / \mathrm{MWh}
\end{aligned}
$$

This equation is based on option A of the operating margin emission factor calculation of the CDM tool for calculating emission factors from electrical systems (United Nations Framework Convention on Climate Change Clean Development Methodology Panel 2007a). The simple OM emission factor calculation method was selected by way of elimination and comparison:

- The adjusted simple OM emission factor method was not used because it has much more detailed use of low-cost/must-run plants, which is almost irrelevant given the negligible generation of the single $275 \mathrm{~kW}$ test wind turbine at Devil's Point in 2007 as the only low-cost/must-run plant;

- the dispatch data OM emission factor methodology was not used because it is a dispatch order method that can only be used with ex-post data rather than exante historical data; and 
- the average OM emission factor methodology was not used because it is more complicated than the simple OM method, requiring estimation of the wind turbine data.

The default values for the net calorific value of fossil diesel and the emissions factor of fossil diesel were taken from the revised 1996 IPCC guidelines for national greenhouse gas inventories as is standard for the CDM (Intergovernmental Panel on Climate Change 2006). Generation data from the wind turbine at Devil's Point is not necessary because it is classified as a low-cost/must-run plant, which is not used in the equation under option $\mathrm{A}$ for the calculation of the operating margin emission factor.

In the situation of the Vanuatu fuel swap project the build margin consists of the set of five power units that have been built most recently. A power unit is defined in the tool as an individual electricity generator; however multiple power units are considered a single power unit if they are identical in technology, fuel type, rated capacity and commissioning date. This study assumes that the two diesel generators are considered as two separate power units on the basis that they were planned together but were commissioned 22 months apart from each other. The last five power units are the $275 \mathrm{~kW}$ test wind turbine, the two $4 \mathrm{MW}$ generators at Tagabe, and the two most recently installed power units at the Unelco generation facility in the central business district of Port Vila. If the Vanuatu fuel swap project is delayed and 2008 is included, then the building margin will be less emission intensive with the inclusion of the new Devil's Point wind farm.

Following the definition of power unit, the five most recently commissioned power units from 2009 would be $2.75 \mathrm{MW}$ of capacity from the ten wind turbines to be installed in $2008,275 \mathrm{~kW}$ of capacity from the test turbine erected in 2007 , the two generators at Tagabe - accounting for their use of coconut oil - and the most recently built power unit at the Port Vila central business district generation plant. The build margin (BM) has only two methodology options: the use of either ex ante or ex post data. The most accurate estimate of the potential build margin will thus be generated by this analysis using the data that is already available, in an ex-ante fashion. The BM will be less emission intensive because of the inclusion of a wind turbine and because 
of the higher proportion of coconut oil in the diesel generators as some fossil dieselonly generators are excluded. The BM is less accurate than the OM because electricity generation data is not publicly available for individual power generation units. The proportion of thermal generation from the newest four diesel generators is conservatively estimated at $85 \%$ for the purposes of this study. Combining the estimate of $85 \%$ with the data and assumptions made in the calculation of the OM gives a generation from the four diesel generators included in the BM of $34,498.2 \mathrm{MWh}$ from $8,839.5 \mathrm{~kL}$ of fossil diesel as well as the raw coconut oil used at Tagabe. The load factor of the wind turbine is estimated to be $25 \%$, which gives an annual generation of 602MWh per year. The wind turbine was operating for approximately seven months in 2007, which equates to an estimate of $350.35 \mathrm{MWh}$ of electricity generation. From these data, estimates and assumptions, the BM can be calculated as in Equation 10.

EQUATION 10: BASELINE METHODOLOGY CALCULATION

$$
E F_{\text {grid }, B M}=\frac{8839.5 \times\left(43.33 \times 20.2 \times 0.99 \times \frac{44}{12} \times 10^{-3}\right)}{34498.2+350.35}=0.806 t \mathrm{CO}_{2} / \mathrm{MWh}
$$

The UNFCCC EB's tool for calculating the emission factor of electrical systems suggests that the combined margin (CM) emissions factor be calculated using an equal weighting of $\mathrm{BM}$ and $\mathrm{OM}$ for the first crediting period and weighting $75 \% \mathrm{BM}$ and $25 \% \mathrm{OM}$ thereafter. The first crediting period will hence use a combined margin emission factor of $0.849 \mathrm{tCO}_{2} / \mathrm{MWh}$ while $0.827 \mathrm{tCO}_{2} / \mathrm{MWh}$ will be used for the second crediting period.

\section{LEAKAGE}

Leakage is a change in the global level of greenhouse gas emissions indirectly due to the CDM project activity. Leakage is assessed under the guidelines documented by the UNFCCC EB and agreed to within the fourth decision by the UNFCCC conference of the parties of the UNFCCC serving as the meeting of the parties to the Kyoto Protocol at its first session (United Nations Framework Convention on Climate Change 2005). 
Under the guidelines of the UNFCCC the Vanuatu fuel swap methodology should account for two categories of leakage: 'Shift of pre-project activities' and 'Emissions from biomass generation/cultivation'.

Research by CIRAD shows that with good litter management the coconut palm plantations in Vanuatu have a net negative carbon flux (Hamel et al. 2004). Within the project boundary defined as the coconut palm plantations, the biodiesel plant and the Unelco generators the emissions from the transport and distribution of biodiesel and its intermediate products is not included. This is appropriate given that the transport and distribution emissions for fossil diesel are excluded from the baseline calculation. These emissions can also be neglected under the guidance of the UNFCCC, which assumes these emissions to be smaller than ten percent.

The coconuts are processed into copra manually and dried using heat generated from renewable wood, resulting in zero greenhouse gas emissions. Figure 6 shows a typical wood fired copra dryer. The main potential source of emissions from the biodiesel refinery is from the use of electricity. However, it is likely that the level of emissions from electricity using a weighted average emission factor would likely be negligible because the majority of the electricity in Santo is generated from a hydro dam. Therefore, the total leakage for the second category is negative. However, it is unlikely that the Executive Board would approve a negative leakage, so the leakage from the generation and processing of the biomass is assumed to be zero. This result is consistent with the suggestion by the UNFCCC that the significant sources of emissions can be fertilizer use and land clearance, which are zero in the Vanuatu fuel swap scenario. 


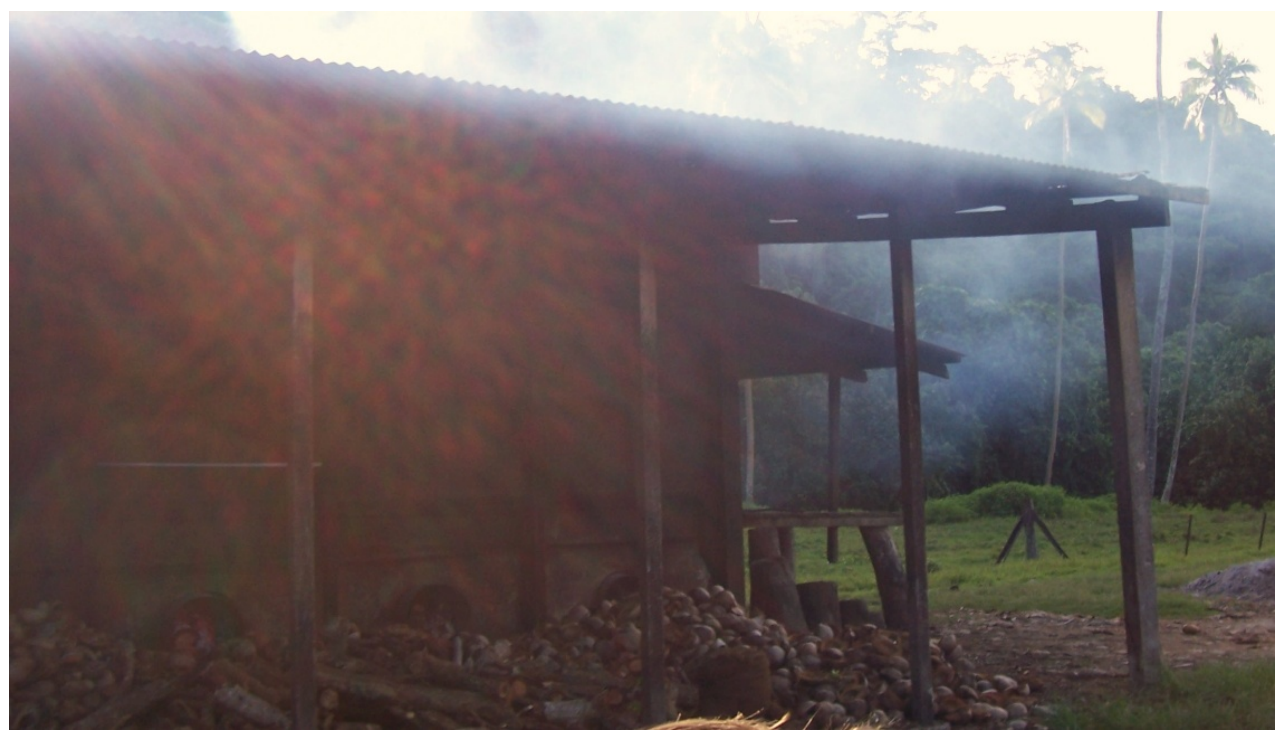

The leakage from the first category - 'Shifts of pre-project activities' - is also zero. The guidance from the UNFCCC suggests that this category can be neglected if the land use within the project boundary remains the same, which is the case is given that it has been shown that the current Vanuatu coconut palm plantations are sufficient to produce the coconut oil required. Further, the same farmers that are producing copra for export will instead be producing copra for biodiesel, meaning that no people or their economic activity will be displaced to another area. Figure 7 is an example of land that is already established in Vanuatu as a coconut plantation.

FIGURE 7: COCONUT PLANTATION ON THE ISLAND OF SANTO IN VANUATU

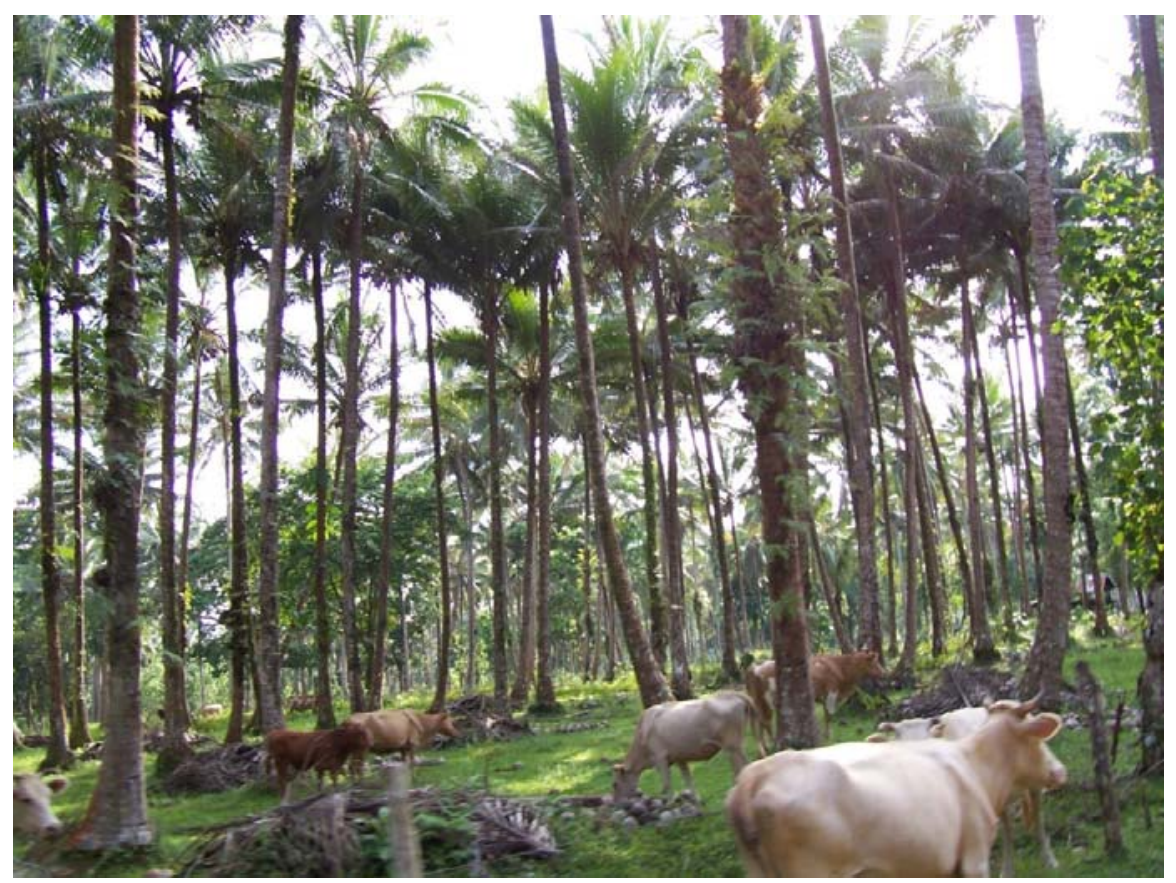


The methodology AMS.I.D. does not have specific guidelines on the method for calculating emissions from the project activity where the source of electricity generation is only partially renewable. However, the large scale methodology AM0047 describes a method of doing so specifically for the scenario in which natural gas sourced methanol is used in the production of biodiesel.

AM0047 gives the formula for the calculation of the project emissions from combustion of fossil fuel derived methanol in the biodiesel ester in Equation 11.

EQUATION 11: EMISSIONS FROM METHANOL (FROM AM0047)

$$
\text { Project Emissions }=\operatorname{Mass}_{\mathrm{MeOH}} \times \frac{12}{32} \times \frac{44}{12}=\operatorname{Mass}_{\mathrm{MeOH}} \times \frac{11}{8}
$$

The Vanuatu fuel swap model assumes that 880 tonnes of methanol is required in order to produce ten million litres of biodiesel. Using the formula from AM0047, the 880 tonnes of methanol per year would be responsible for $1,210 \mathrm{tCO}_{2} \mathrm{e}$ per year.

Assuming that a methodology was available that created a project boundary covering the full ten million litres of biodiesel per year, this analysis applies the CM emission factor to the projected electricity generation over the project's life to calculate the number of CER's generated for sale before leakage is accounted for.

\section{CER VOLUME}

The total CER volume is the baseline emissions minus the leakage and project emissions. In order to apply the CM grid emission factor to calculate the baseline emissions, the Vanuatu fuel swap model estimates the MWhs of electricity generation attributable to the ten million litres of biodiesel per year. Methodology AM0047, which is written specifically for a scenario in which fossil diesel use is displaced by transesterified biodiesel, compares the net calorific value of biodiesel to fossil diesel to calculate the displacement conversion factor between the two fuels. The revised 1996 IPCC guidelines for greenhouse gas accounting give a net calorific value of fossil diesel of 43.33TJ/kt, but do not give a value for transesterified biodiesel (Intergovernmental Panel on Climate 
Change 2006). Culaba et al. (2004) use net calorific values of 42TJ/kt for fossil diesel and $38 \mathrm{TJ} / \mathrm{kt}$ for biodiesel.

The Vanuatu fuel swap uses the Culaba et al. (2004) net calorific values for the purpose of comparing the two fuels because it is the consistent comparison rather than the absolute values that is required. Therefore, the Vanuatu fuel swap model assumes that one tonne of biodiesel generates $9.52 \%$ less MWhs of electricity than fossil diesel. Based on these assumptions, Table 9 shows the projected annual generation of CERs from the proposed Vanuatu fuel swap CDM project activity. 


\begin{tabular}{|c|c|c|c|c|c|c|c|c|c|}
\hline \multirow{2}{*}{ Year } & \multirow{2}{*}{$\begin{array}{c}\text { Biodiesel } \\
\text { litres }\end{array}$} & \multirow{2}{*}{$\begin{array}{c}\text { Biodiesel } \\
\qquad \mathrm{Kg}\end{array}$} & \multicolumn{2}{|c|}{ Fossil diesel displaced } & \multirow{2}{*}{$\begin{array}{c}\text { Electricity } \\
\text { generated } \\
\text { MWhs }\end{array}$} & \multirow{2}{*}{$\begin{array}{c}\text { Emissions } \\
\text { Factor } \\
\text { tonnes/MWh }\end{array}$} & \multirow{2}{*}{$\begin{array}{c}\text { Baseline } \\
\text { tonnes }\end{array}$} & \multirow{2}{*}{$\begin{array}{c}\text { GHG from } \\
\text { methanol } \\
\text { tonnes } \mathrm{CO}_{2} \mathrm{e}\end{array}$} & \multirow{2}{*}{ CERs } \\
\hline & & & Litres & $\mathrm{kg}$ & & & & & \\
\hline 2009 & $10,000,000$ & $8,800,000$ & $9,478,458$ & $7,961,905$ & 32,640 & 0.849 & 27,711 & 1,210 & 26,501 \\
\hline 2010 & $10,000,000$ & $8,800,000$ & $9,478,458$ & $7,961,905$ & 32,640 & 0.849 & 27,711 & 1,210 & 26,501 \\
\hline 2011 & $10,000,000$ & $8,800,000$ & $9,478,458$ & $7,961,905$ & 32,640 & 0.849 & 27,711 & 1,210 & 26,501 \\
\hline 2012 & $10,000,000$ & $8,800,000$ & $9,478,458$ & $7,961,905$ & 32,640 & 0.849 & 27,711 & 1,210 & 26,501 \\
\hline 2013 & $10,000,000$ & $8,800,000$ & $9,478,458$ & $7,961,905$ & 32,640 & 0.849 & 27,711 & 1,210 & 26,501 \\
\hline 2014 & $10,000,000$ & $8,800,000$ & $9,478,458$ & $7,961,905$ & 32,640 & 0.849 & 27,711 & 1,210 & 26,501 \\
\hline 2015 & $10,000,000$ & $8,800,000$ & $9,478,458$ & $7,961,905$ & 32,640 & 0.849 & 27,711 & 1,210 & 26,501 \\
\hline 2016 & $10,000,000$ & $8,800,000$ & $9,478,458$ & $7,961,905$ & 32,640 & 0.827 & 26,993 & 1,210 & 25,783 \\
\hline 2017 & $10,000,000$ & $8,800,000$ & $9,478,458$ & $7,961,905$ & 32,640 & 0.827 & 26,993 & 1,210 & 25,783 \\
\hline 2018 & $10,000,000$ & $8,800,000$ & $9,478,458$ & $7,961,905$ & 32,640 & 0.827 & 26,993 & 1,210 & 25,783 \\
\hline 2019 & $10,000,000$ & $8,800,000$ & $9,478,458$ & $7,961,905$ & 32,640 & 0.827 & 26,993 & 1,210 & 25,783 \\
\hline 2020 & $10,000,000$ & $8,800,000$ & $9,478,458$ & $7,961,905$ & 32,640 & 0.827 & 26,993 & 1,210 & 25,783 \\
\hline 2021 & $10,000,000$ & $8,800,000$ & $9,478,458$ & $7,961,905$ & 32,640 & 0.827 & 26,993 & 1,210 & 25,783 \\
\hline 2022 & $10,000,000$ & $8,800,000$ & $9,478,458$ & $7,961,905$ & 32,640 & 0.827 & 26,993 & 1,210 & 25,783 \\
\hline 2023 & $10,000,000$ & $8,800,000$ & $9,478,458$ & $7,961,905$ & 32,640 & 0.827 & 26,993 & 1,210 & 25,783 \\
\hline TOTAL & $150,000,000$ & $132,000,000$ & $142,176,871$ & $119,428,571$ & 489,596 & & 409,923 & 18,150 & 391,773 \\
\hline
\end{tabular}


Table 9 shows that the projected generation of CERs by the proposed Vanuatu fuel swap CDM project over the fifteen year lifespan of the biodiesel refinery is 391,773 tonnes. The total nominal non-discounted value of the 391,773 CERs is projected to be $7,535,774$ USD and their present value - using the discount rate of $17.8 \%$ from the financial analysis - projected to be 2,887,613 USD. This present value would significantly outweigh any transaction costs if they could not be covered by other sources of carbon finance.

\section{VOLUNTARY CARBON MARKET}

The large majority of voluntary carbon market standards will accept projects that reach or exceed the standards of the CDM. That is, they will accept projects that pass the CDM additionality test and use a baseline and monitoring methodology that has been approved by the CDM EB. There are also some boutique voluntary carbon market standards that have higher standards than the CDM for some project components. The Verified Emission Reductions (VERs) from these boutique standards can fetch higher prices than CERs because of their superior integrity. Some of the higher-quality VERs are of a higher overall environmental integrity because of the co-benefits attached to the standard such as biodiversity for forestry projects.

There are several reasons why a CDM project developer may choose to apply to a voluntary carbon market standards organisation to generate VERs rather than generate CERs under the CDM. As aforementioned, high quality projects may meet standards higher than those set by the CDM (the compliance market) thus garnering higher prices. At the other end of the scale, some voluntary carbon standard organisations have lower standards than that of the compliance market. This may be attractive to a developer who cannot meet the strict additionality or methodology requirements of the compliance market. The lower standards may also be attractive to projects that could be eligible for compliance market credits because of the lower compliance costs involved with lower quality voluntary emission reductions. In this case the project developer must weigh up the saving in compliance cost against the loss in revenue from the lower price of the resulting VERs. The lower compliance costs are also particularly attractive to the project developers of smaller projects that do not reach the economy of scale required to make the investment in compliance market CDM administration worthwhile for the generation of CERs. 
There are potential co-benefits that the Vanuatu fuel swap project may be able to draw on for additional value within the carbon market framework, which could only be accounted for in the voluntary carbon market. As discussed in the introduction, the Vanuatu fuel swap would have multiple benefits in terms of sustainable development in Vanuatu. In particular the fuel swap would be an environmentally friendly income source for farmers. Growing coconut plantations for biodiesel production is not only environmentally beneficial because of the carbon difference between using biofuels and fossil fuels. It is also environmentally beneficial because of the carbon sequestered in the coconut plantations that is greater than the sequestered carbon in the farmer's alternative agricultural options. Other popular agricultural options for land in Vanuatu include kava and cattle. Both of these have less carbon held in plant matter than in coconut plantations. It has also been shown by Hamel et al. (2004) that high quality litter management by the coconut plantation farmer will result in a net negative carbon flux of the coconut plantation due to the increase in soil carbon. The Centre de Coopération Internationale en Recherche Agronomique pour le Developpement (CIRAD) has also successfully conducted research on the opportunities available to copra farmers by utilizing the land between coconut trees within a coconut plantation for other agriculture such as the nangai nut. The growth of these additional nitrogen fixing crops will sequester additional carbon as well as improving the fertility of the soil. Under the carbon accounting practices of the Kyoto Protocol, the carbon sequestered by agricultural crops - even perennial crops such as coconut trees - cannot be accounted for in national greenhouse gas inventories, CDM projects, or JI projects. Under the Kyoto Protocol changes in the amount of carbon in soil matter are not accounted for either. Some standards in the voluntary market will account for sequestration from agroforestry projects.

\section{CARBON FINANCE OPPORTUNITIES OUTSIDE THE CARBON CREDIT MARKET}

As a result of the positive externalities from the production of energy from renewable sources when compared to fossil fuel alternatives there are a number of organisations that donate financial aid to renewable energy projects in developing countries. Some of the organisations give straight grants while others give finance to projects that would 
generally be considered unattractive to regular sources of finance. Both types of organisations could be approached for funding by the Government of Vanuatu or a project developer of the Vanuatu fuel swap. The following is a list of organisations that support projects such as the proposed Vanuatu fuel swap.

The Global Energy Efficiency and Renewable Energy Fund (GEEREF) is a finance lender, within the European Investment Bank (EIB). GEEREF is a funder of funds, which means that renewable energy project developers can approach GEEREF to assist a regular financier in providing finance to an otherwise unattractive project. In order to make the project attractive to the regular financier, the GEEREF will take on a higher level of risk within the project. GEEREF is particularly well suited to the Vanuatu fuel swap because it is aimed towards projects of one to ten million Euros because of a perceived void in available finance for projects of this size.

The Renewable Energy and Energy Efficiency Partnership (REEEP) does not directly support individual renewable energy projects; instead it is primarily a funder of capacity-building projects. This could be useful in Vanuatu specifically for issues around the fuel swap - such as supporting the development of a new CDM baseline and monitoring methodology - or more generally for Vanuatu, the Pacific Region or SIDS. The Vanuatu Government could apply directly, or an organisation involved in renewable energy capacity building and research could apply for financial support to carry out a project in Vanuatu. REEEP could be a very useful funder for financing the capacity building and research required to enable significant carbon finance to be procured from elsewhere.

The official development assistance (ODA) organisations of many developed countries seek projects that meet the criteria reached by the Vanuatu fuel swap project.

Sustainable energy supply in developing countries is specifically referred to by the World Bank as a crucial factor in meeting the Millennium Development Goals (MDGs). In particular, the relevant characteristics that are commonly supported by foreign aid include rural development, sustainable development, climate change mitigation, energy independence, and renewable energy. The national foreign development aid agencies that could be approached include the Australian Agency for International Development 
(AusAID), the United States Agency for International Development (USAID), and the New Zealand Agency for International Aid (NZAID).

The ODA from developed European countries is directed through various agencies and institutions. For example the British government uses government money to fund its own ODA programmes, such as the Strategic Programme Fund, as well as funding EU ODA initiatives. The largest European ODA initiative is the European Development Fund (EDF), which is administered by the European Commission (EC). The British Government also supports international initiatives including the International Monetary Fund (IMF). A number of banks have been established specifically for development, such as the World Bank and the Asia Development Bank (ADB). These banks give loans to projects in developing countries in situations that regular profitable financial institutions would not cover, where the project contributes to the host country's development. 


\section{CONCEPTUAL FRAMEWORK}

The conceptual framework that this research is based within is a holistic action research framework that focuses on pragmatic outcomes rather than theoretical developments. It is this perspective that is used to draw understanding from the specific results found in the results section of the thesis.

\section{ECONOMIC FEASIBILITY}

The economic feasibility analysis is not a full cost-benefit analysis (i.e. it does not include environmental costs and benefits that are not currently priced in the monetary economy) of the proposed fuel swap; it is a financial analysis that aims to mimic what would be carried out by prospective investors in a best industry level of practice. Through the course of this thesis, however, an element of qualitative cost-benefit analysis has been employed as a parallel exercise. The research shows that stakeholders believe that there are many external and third party benefits from domestic production of biodiesel and were therefore very supportive. However, the research also showed that stakeholders that have the potential to lead the development of a biofuel industry in Vanuatu - Unelco, CLA-CC, and the Vanuatu Government - all believe that external financing is required to support the project.

Unelco looks closely at financial profitability. CLA-CC has a more qualitative and generalist approach to business, seeing a local biofuel industry as a promising industry given perceived economic and political trends. However, neither CLA-CC nor UNELCO have sufficient capital equity to develop a biodiesel refinery without external financing.

This study shows that, given the use of the CDM, a fuel swap could be financially feasible and should therefore provoke interest in investors. 
The Government of Vanuatu is generally supportive of the development of biofuels. However, the government is under-resourced and has not yet been sufficiently organised to ensure the success of large scale biofuel developments. Poor communication is a large cause of bureaucratic inefficiency across the Government's Ministries, with a lack of cross-departmental cooperation. This poor communication appears to be due to both a low level of physical telecommunications infrastructure as well as a lack of human resources. The Governmental rhetoric is resoundingly supportive of a local biofuel industry; however there are also sections of the Government of Vanuatu that indirectly impose barriers to the development of a vibrant biofuel sector. The operations of the Government's Vanuatu Commodities Marketing Board (VCMB), for example, have consistently undermined value-added agricultural manufacturing in Vanuatu. The VCMB effectively subsidises raw copra exports and copra for its own small coconut oil and soap production branch, Vanuatu Copra Processing Limited (VCPL). Private domestic processors of copra do not receive a subsidy and thus cannot compete with the VCMB for purchasing copra from farmers. Several years ago the former owners of the Luganville coconut oil mill were forced to import copra from the Solomon Islands while the VCMB exported raw copra. Some of the people interviewed for this research believe that this situation was a large factor in the business failure of the past owners of the Luganville oil mill.

A potential solution that would not take a drastic amount of change would be for the VCMB to open up the wholesale copra market by selling subsidized copra to local processors as well as exporters. However, this would require improved systems rather than simply buying and selling copra, because unlimited opportunities of arbitrage would be created if the VCMB was buying copra at a higher price than it was selling it for. Expanding the wholesale market would mean that coconut oil and coconut-based biodiesel producers could purchase copra at the same price as copra exporters so that domestic users of copra can compete with exporters in purchasing copra.

There are several other policies of the Government of Vanuatu that also remove potential incentives to the development of a biodiesel industry by supporting Unelco. These policies are contained in the concessional agreement between the Government and 
Unelco. In particular, the Government guarantees the monopoly status of Unelco for electricity generation, distribution, and retail in Port Vila until 2031. The monopoly status of Unelco implies that the company can easily change prices to cover the cost of fossil diesel. Without competition there is no need for Unelco to consider investment in alternative means of generation to replace fossil diesel generation.

In November 2007 the Parliament of Vanuatu endorsed the creation of a utility regulators authority, which may have some regulatory power over the electricity price. It is unclear yet whether this endorsement has had an effect on the Vanuatu electricity market. If the price of fossil diesel continues to rise the Utility Regulators Authority may be able to force the electricity generator to provide electricity at the least cost available, which may be the price that it would cost to use biodiesel. To be successful it is important that the new Authority is supported to develop sufficient human capacity.

A second element of the concessional agreement is that the Government of Vanuatu allows the electricity generator to import fossil diesel for electricity generation without paying any import duty or fossil fuel tax. Unelco must still pay regular VAT on the imported fossil diesel. If the Government were to include further indirect tax on the purchase of fossil diesel for electricity consumption then locally produced biodiesel would become much more competitive. The aim of the import duty across most products is to incentivise the purchase of local produce. In accordance with this principle, manufacturing equipment to be used for local manufacturing is free of import duty so as to further encourage local production. For example, imported equipment required for the proposed biodiesel refinery would be free of import duty.

The concession on fossil diesel import duties was made in a time when there were no other economically feasible alternatives to fossil diesel for electricity production. Thus the import duty would not have encouraged local production as there was no local substitute. However, now that there is a local substitute that has been shown to be feasible, it would be wise for the Government to reintroduce the import duty on fossil diesel in future concession agreements. However, the Vila concession to 2031 means that in the meantime the Government of Vanuatu must find ways to co-operate with Unelco in order to ensure the optimal outcome for Ni-Vanuatu. 
The carbon finance analysis showed that the proposed biodiesel refinery could be a credible CDM project by passing the test of additionality and generating a significant volume of CERs. It also showed that recognition of the co-benefits of the development of a Vanuatu biofuel industry would open up several other sources of finance that could be further explored by entrepreneurs to support the development of a large scale biodiesel refinery business in Vanuatu.

The results have interesting implications for international post-2012 climate change treaty negotiations. The results clearly show that the fuel swap in Vanuatu is a classic case where the CDM should work in regards to technology transfer to developing countries and sustainable development. The fuel swap would require technology that is successfully used in other countries and revenue that the CERs generate to make the project profitable. However, the project - a low hanging fruit of climate change mitigation - has not yet happened.

The fact that the fuel swap from fossil diesel to biodiesel has not yet happened in Vanuatu means that there are other barriers to uptake. In this study, some of these barriers are discussed in the additionality section of the CDM analysis. However, this does not necessarily mean that the revenue generated from CERs is sufficient to overcome these barriers.

While this study recommends that the CDM be continued in one form or another in a post-2012 climate change treaty, climate change negotiations must be cognizant of the limitations of the CDM. It is important to recognise that the global market for climate change mitigation is far from perfect; the other barriers to market efficiency must also be addressed if dangerous anthropogenic climate change is to be avoided. Two examples of programmes that address these other barriers are raised in the alternative funding section of the CDM analysis in this study: REEEP and GEREEF. The primary limitation of these programmes - and others like them - is funding. Therefore, post-2012 climate change treaty negotiations should include discussion on the funding of programmes to overcome non-financial barriers to the uptake of renewable energy and energy efficiency in developing countries. 
While the financial analysis presented in this thesis may seem a disappointing outcome, the result of the carbon finance analysis puts it into a new perspective. The estimated net present value shortfall of the investment that was shown in the financial feasibility analysis can be offset by the opportunity for carbon finance that is explored in the carbon finance section.

The feasibility study element of this thesis will be a useful tool for empowering the key stakeholders to make better informed economic decisions around investments in Vanuatu's energy infrastructure. This additional information may also increase the negotiating power of the Government of Vanuatu in their relationship with the electricity generator UNELCO.

This empowerment through information will be furthered by the preliminary carbon finance assessment. This will help the relevant stakeholders decide whether or not they should pursue a carbon finance transaction and whether carbon finance capacity building in the region would be beneficial. By formally identifying and analysing the barriers to completing a carbon finance transaction in Vanuatu, the thesis helps demystify the subject thereby facilitating progress towards utilization of the growing carbon market for purposes of sustainable development and energy security in a Pacific Island State. 


\section{CONCLUSIONS/RECOMMENDATIONS}

The results of this research of the Vanuatu fuel swap model clearly show that all stakeholders should view a large scale coconut-based biodiesel refinery in Vanuatu as a valid alternative to the status quo. Stakeholders who may benefit from the results of this research when making strategic decisions regarding the use of biofuel for grid-connected electricity generation include the Vanuatu Government, electricity generators, potential project developers, and potential funders.

While the absolute dollar results of the economic feasibility study are important, the most important result from this section of the research is the establishment of the Vanuatu fuel swap model. This model sets a baseline for future research and analysis. The model will need to be updated as technology, price projections, and policy settings change. In particular, users of the model are recommended to use the most recently available oil and coconut price projections (as well as alternative price scenarios) in order to evaluate the profitability of a Vanuatu biodiesel industry.

Accordingly, the information gained from this research is not transformed into a strict set of recommendations for an individual project or party. The information is intended to act as a catalyst to empower the relevant parties to act together to develop a biodiesel industry that is of benefit to them as well as the Vanuatu community. From this conclusion, however, does come one specific recommendation. Because this research is relevant to so many stakeholders - with large implications and opportunities for them this thesis recommends that the relevant stakeholders begin a series of communications with each other using this thesis as a starting point for a discussion. This is important because - as this thesis shows - the Vanuatu context is a complicated one, meaning that there are several aspects that need to be addressed in order for the proposal to move forward. A suitable focal point for this co-operative discourse would be the Vanuatu National Advisory Climate Change Committee (NACCC). 
Allen, F., Brealey R., Myers, S. 2006. Principles of Corporate Finance, Eighth Edition. McGraw-Hill; New York, NY: 2006.

Alves, L.M., Chen, F., Duic, N., and da Graça Carvalho, M. 2003. Potential of Kyoto Protocol Clean Development Mechanism in transfer of clean energy technologies to Small Island developing states: case study of Cape Verde: Renewable and Sustainable Energy Reviews 7: 83-98.

Bakker, S. 2006. CDM and biofuels - Can the CDM assist biofuel production and deployment? [Online]. Retrieved February 12, 2008, from http://www.ecn.nl/docs/library/report/2006/e06033.pdf

Balachandra P., Dasappa, S., Ravindranath, N.H., and Usha Rao, K. 2006. Bioenergy technologies for carbon abatement: Biomass \& Bioenergy 30: 826-837.

Bazley, M., Berry, A., Hancock, P., and Jarvis, R. 2001. Contemporary Accounting, Fourth Edition. Nelson Thomson Learning: Victoria, Australia.

Bhandari, P., Gupta, P., and Kishore, V. 2004. Biomass energy technologies for rural infrastructure and village power-opportunities and challenges in the context of global climate change concerns: Energy Policy 32: 801-810.

Biofuels International. 2007. India's First Biodiesel Plant Starts Production. [Online]. Retrieved November 16 $16^{\text {th }}, 2008$ from http://www.biofuelsnews.com/news/india firstbio.html.

Bradley, R., Childs, B. 2007. Plants at the Pump: Biofuels, Climate Change, and Sustainability. World Resources Institute: Washington.

Caputo, A., and Pelagagge, P. 2000. Waste-to-energy plant for paper industry sludges disposal: technical economic study: Journal of Hazardous Materials B81: 265-283.

Carbonpositive. 2008. CER prices mark time in March. [Online]. Retrieved 11 April, 2008, from http://www.carbonpositive.net/viewarticle.aspx?articleID=137.

Carlin, W. and Soskice D. 2006. Macroeconomics: Imperfections, Institutions, \& Policies. Oxford University Press: Oxford and New York.

Clarke, D. 2007. The battle for barrels: Peak oil myths \& world oil futures. London: Profile Books Ltd.

Clements, D., van Gerpen, J., Knothe, G., Pruszko, R., and Shanks, B. 2006. Building a Successful Biodiesel Business: Second Edition. Iowa: Biodiesel Basics.

Cloin, J. 2005. Biofuels in the Pacific: Refocus 6, (4): 45-48.

Cloin, J. 2006. SOPAC Annual Session STAR Paper: Overview of Pacific regional biofuel activities. [Online]. Retrieved January 25, 2008, 
from www.unesco.org/csi/smis/siv/Forum/BiofuelOverview-STAR2006JanCloin.pdf

Council of Ministers of the Government of Vanuatu. 2000. Vanuatu's vision for a 100\% renewable energy economy. Government of Vanuatu.

Cruz, F., Dorado, M., Lopez, F., and Palomar, J. 2006. An approach to the economics of two vegetable oil-based biofuels in Spain: Renewable Energy 31: 1231-1237.

Culaba, A., Purvis, M., Tan, R. 2004. Carbon balance implications of coconut biodiesel utilization in the Philippine automotive transport sector: Biomass and Bioenergy 26: 579-585.

Demirbas, A. 2007. Importance of biodiesel as transportation fuel: Energy Policy 35: 4661-4670.

European Commission. 2008. Climate Action, Energy for a Changing World: More Renewable Energy. [Online]. Retrieved November 18 ${ }^{\text {th }}, 2008$ from http://ec.europa.eu/climateaction/eu action/renewable energy/index en.h $\underline{\mathrm{tm}}$.

Fenhann, J. 2008. CDM Pipeline. [Online]. Retrieved March 25, 2008, from http://cdmpipeline.org/

Fortenbery, T. 2005. Biodiesel feasibility study: An evaluation of biodiesel feasibility in Wisconsin. Staff Paper No. 481 in the Agricultural and Applied Economics Staff Paper Series of the University of Wisconsin-Madison.

Gan, L., and Yu, J. 2008. Bioenergy transition in rural china: Policy options and cobenefits: Energy Policy 36: 531-540.

Glover, L. 2006. Postmodern climate change. New York: Routledge.

Grootveld, H., Salomons, R. 2003. The equity risk premium: emerging vs. developed markets: Emerging Markets Review 4: 121-144.

Gustavsson, L., and Madlener, R. 2003. $\mathrm{CO}_{2}$ mitigation costs of large-scale bioenergy technologies in competitive electricity markets: Energy 28: 1405-1425.

Hamada, R. 1972. The effect of the firm's capital structure on the systematic risk of common stocks: The Journal of Finance 27 (2): 435-452.

Hamel, O., Labouisse, J., Lamanda, N., Roupsard, O., and Rouziere, A. 2004. Preparing the application of coconut plantation to the Clean Development Mechanism of the Kyoto Protocol. In: Rethinam Ponniah (ed). Strategies for enhancing productivity and income of coconut farmers: Proceedings of the forty-first Cocotech meeting, 5-9 July 2004, Santo, Vanuatu: 164-179. Jakarta: Asian and Pacific Coconut Community.

Herold, M. 2007. Personal Communication, December 2007. 
Hill, J., Nelson, E., Tilman, D., Polasky, S., and Tiffany, D. 2006. Environmental, economic, and energetic costs of biodiesel and ethanol biofuels: PNAS 103, (30): 1120611210.

Intergovernmental Panel on Climate Change. 2007. Climate Change 2007: The Physical Science Basis, Contribution of Working Group I to the Fourth Assessment Report of the Intergovernmental Panel on Climate Change. Cambridge, United Kingdom and New York, NY, USA, Cambridge University Press.

Intergovernmental Panel on Climate Change. 2006. Revised 1996 IPCC Guidelines for National Greenhouse Gas Inventories: Reference Manual (Volume 3). [Online]. Retrieved 9 October, 2007, from http://www.ipccnggip.iges.or.jp/public/gl/invs6.htm.

International Energy Agency. 2007a. Medium-term oil market report: July 2007. Paris: International Energy Agency.

International Energy Agency, 2007b. World Energy Outlook 2007: China and India Insights. Paris: International Energy Agency.

Islas, I., Manzini, F., and Masera, 0. 2007. A prospective study of bioenergy use in Mexico: Energy 32: 2306-2320.

van Kasteren, J., and Nisworo, A. 2007. A process model to estimate the cost of industrial scale biodiesel production from waste cooking oil by supercritical transesterification: Resources Conservation \& Recycling 50: 442-458.

Ki-moon, B. 2007. Address to General Assembly thematic debate: "Climate Change as a Global Challenge". [Online]. Retrieved 15 August, 2007, from http://www.un.org/apps/news/infocus/sgspeeches/search full.asp?statID $=105$

KPMG. 2007. KPMG's Corporate and Indirect Tax Rate Survey 2007. Switzerland: KPMG.

Labouisse, J., Lamanda, N., Roupsard, O., and Rouziere, A. 2004. For a new coconut research and development strategy in Vanuatu. In Rethinam Ponniah (ed.). Strategies for enhancing productivity and income of coconut farmers: Proceedings of the forty-first Cocotech meeting, 5-9 July 2004, Santo, Vanuatu: 111-126. Jakarta: Asian and Pacific Coconut Community.

Lin, C., Tsai, W., and Yeh, C. 2007. An analysis of biodiesel fuel from waste edible oil in Taiwan: Renewable \& Sustainable Energy Reviews 11: 838-857

Mapquest. 2006. Vanuatu. [Online] Retrieved 1 November, 2008, from http://go.hrw.com/atlas/norm htm/vanuatu.htm\#facts

Methanex. 2008. Historical methane posted prices (PDF). [Online]. Retrieved 10 February, 2008, from http://www.methanex.com/products/methanolprice.html.

Nelson, R., and Schrock, M. 2006. Energetic and economic feasibility associated with the production, processing, and conversion of beef tallow to a substitute diesel fuel: Biomass and Bioenergy 30: 584-591. 
Pacione, M. 1999. In pursuit of useful knowledge: the principles and practice of applied geography. In: Pacione, M. (ed.). 1999. Applied Geography: Principles and practice. London; New York: Routledge.

Pokharel, S. 2006. Kyoto Protocol and Nepal's energy sector: Energy Policy 35: 25142525.

Reserve Bank of New Zealand. 2008. Exchange rates and foreign exchange turnover. [Online]. Retrieved 11 April, 2008 from http://www.rbnz.govt.nz/statistics/exandint/b1/.

Reuters 2008. Live stock information for Allegro Biodiesel Corporation. [Online]. Retrieved 12 ${ }^{\text {th }}$ May, 2008.

Rowland, W. 2005. Greed, Inc.: why corporations rule our world. New York, NY, USA: Arcade Publishing.

Secretariat of the Pacific Regional Environment Programme, 2004. Pacific Islands Renewable Energy Project: Pacific Regional Energy Assessment 2004: Vanuatu national report. Suva: SPREP.

Sims, R. 2002. The Brilliance of Bioenergy: In Business and in Practice. London: James \& James (Science Publishers) Ltd.

Stern, N. 2007. The economics of climate change: The Stern review. Cambridge: Cambridge University Press.

Strahan, D. 2007. The last oil shock: A survival guide to the imminent extinction of petroleum man. London: John Murray (Publishers).

United Nations Framework Convention on Climate Change. 2005. General guidance on leakage in biomass project activities. Attachement $\mathrm{C}$ to Appendix B of Annex II of decision four of the Conference of the parties serving as the meeting of the parties to the Kyoto Protocol at its first session: 28 November 2005 to 10 December 2005, Montreal. [Online] Retrieved 24 October, 2007, from http://cdm.unfccc.int/methodologies/SSCmethodologies/AppB SSC Attach mentC.pdf.

United Nations Framework Convention on Climate Change. 2007. CDM statistics. [Online]. Retrieved 24 August, 2007, from http:cdm.unfccc.int/Statistics/index/html.

United Nations Framework Convention on Climate Change Clean Development Mechanism Methodology Panel. 2007a. Annex 12 to the thirty-fifth meeting of the Executive Board, 15-19 October, 2007: Tool for calculation of emission factor for electrical systems. [Online]. Retrieved 21 January, 2008 from http://cdm.unfccc.int/EB/035/eb35 repan12.pdf.

United Nations Framework Convention on Climate Change Clean Development Mechanism Methodology Panel. 2007b. Approved baseline and monitoring methodology AM0047: "Production of biodiesel based on waste oils and/or waste fats from biogenic origin for use as fuel": AM0047/Version 02. [Online]. Retrieved 
12 February, 2008

from http://cdm.unfccc.int/UserManagement/FileStorage/CDMWF AM LSP8N2A V76VN489R6IUY72YJGTSJL9.

United Nations Framework Convention on Climate Change Clean Development Mechanism Methodology Panel. 2007c. F-CDM-NMSUMmp ver 01 - NM0233. [Online]. Retrieved 14 April, 2008 from http://cdm.unfccc.int/UserManagement/FileStorage/CDMWF MSXYP21JHY S8YS13FNQHQMKM1FX225.

United Nations Framework Convention on Climate Change Clean Development Mechanism Methodology Panel. 2007d. Indicative simplified baseline and monitoring methodologies for selected small-scale CDM project activity categories: Grid connected renewable electricity generation: AMS-I.D/Version 13. [Online]. Retrieved 23 March, 2008 from http://cdm.unfccc.int/UserManagement/FileStorage/CDMWF AM PHPV5W ESACMBTJ2YY54GAJYSIEI3HD.

United States of America Energy Information Administration. 2008. Estimated Consumption of Vehicle Fuels in the United States, by Fuel Type, 2003-2006. [Online]. Retrieved November 18 $8^{\text {th }}, 2008$, from http://www.eia.doe.gov/cneaf/alternate/page/atftables/afvtransfuel II.ht ml\#consumption.

United States of America Federal Reserve. 2008. Federal Reserve statistical release H.15: Selected interest rates, historical data: Market yield on U.S. Treasury securities at 20-year constant maturity, quotes on investment basis, nominal. [Online]. Retrieved 14 April, 2008 from http://www.federalreserve.gov/releases/h15/data.htm.

Vanuatu Daily Post. 2008. UNELCO invests 900 million vatu in a wind farm, published 12 April, 2008. [Online]. Retrieved 20 April, 2008 from http://www.dailypost.vu/index.php?news=2454.

Vanuatu National Statistics Office. 2006. Quarterly statistical indicators - Vanuatu: April June 2006. Government of Vanuatu.

Vergnet Groupe. 2007. Signature of a project at Pointe du Diable, Vanuatu 29/11. [Online]. Retrieved 2 April, 2008

from http://www.vergnet.com/index.php?option=com content\&task=view\&id=1 28\&Itemid=50\&lang=en.

Verweij, M. 2006. Is the Kyoto Protocol merely irrelevant, or positively harmful, for the efforts to curb climate change? In: Thomson, M. and Verweij, M. (eds). 2006. Clumsy Solutions for a Complex World - Governance, Politics and Plural Perceptions. New York: Palgrave Macmillan.

World Bank. 2007. Commodity forecasts (nominal prices). [Online]. Retrieved 10 February, 2008, from http://web.worldbank.org/WBSITE/EXTERNAL/EXTDEC/EXTDECPROSPE CTS/EXTGBLPROSPECTS/0 „contentMDK:20722183 isCURL:Y menuPK:627723 〜pagePK:2904583 piPK:2904598 theSitePK:612501,00.html. 
World Bank, 2008. Vanuatu Data and Statistics. [Online]. Retrieved November $18^{\text {th }}, 2008$ from http://web.worldbank.org/WBSITE/EXTERNAL/COUNTRIES/EASTASIAPA CIFICEXT/PACIFICISLANDSEXTN/0,contentMDK:20217364 menuPK:457024 p agePK:1497618 piPK:217854 theSitePK:441883,00.html. 
TABLE 10: LIST OF INTERVIEWEES

\begin{tabular}{|c|c|c|c|}
\hline Interviewee & Position & Organisation & Comment \\
\hline Alick Berry & Project Manager & $\begin{array}{l}\text { Chamber of Commerce and Industry of } \\
\text { Vanuatu (GoV) }\end{array}$ & \\
\hline Claire Dornic & Owner/Manager & $\begin{array}{l}\text { Claire's Luganville Agencies - Copra } \\
\text { Crushing (CLA-CC) }\end{array}$ & $\begin{array}{l}\text { CLA-CC is the largest copra oil mill in } \\
\text { the Pacific }\end{array}$ \\
\hline David Stein & Head Engineer & $\begin{array}{l}\text { Vanuatu Renewable Energy and Power } \\
\text { Association (VANREPA) }\end{array}$ & \\
\hline Francois Py & $\begin{array}{l}\text { Islands Electricity } \\
\text { Manager }\end{array}$ & Unelco & \\
\hline Gabriel Bani & General Manager & $\begin{array}{l}\text { Vanuatu Commodities Marketing Board } \\
\text { (VCMB) (GoV) }\end{array}$ & $\begin{array}{l}\text { VCMB controls purchase of copra for } \\
\text { export }\end{array}$ \\
\hline John Chaniel & Chief Executive Officer & Unelco Vanuatu & $\begin{array}{l}\text { Unelco has a monopoly on electricity } \\
\text { production and retail in Vila }\end{array}$ \\
\hline Jone Roqara & Sales Manager - Vanuatu & BP South West Pacific & \\
\hline Leo Moli & Principal Energy Officer & Energy Unit (GoV) & \\
\hline $\begin{array}{l}\text { Dr. Olivier } \\
\text { Roupsard }\end{array}$ & Scientist/Researcher & $\begin{array}{l}\text { Centre de coopération internationale en } \\
\text { recherche agronomique pour le } \\
\text { développment (CIRAD) }\end{array}$ & $\begin{array}{l}\text { CIRAD has carried out decades of trials } \\
\text { of different varieties of coconut trees }\end{array}$ \\
\hline Peter Nepwatt & Former Director & Vanuatu Air Sea Transit (VAST) & VAST produced biofuel from coconut oil \\
\hline & Current Principal & Vanuatu College of Agriculture & \\
\hline Queni Signo & $\begin{array}{l}\text { Customs and Internal } \\
\text { Revenue Official }\end{array}$ & $\begin{array}{l}\text { Department of Customs and Internal } \\
\text { Revenue }\end{array}$ & $\begin{array}{l}\text { Customs \& Internal Revenue is in charge } \\
\text { of collecting revenue from fuel imports }\end{array}$ \\
\hline $\begin{array}{l}\text { Stanley } \\
\text { Temakon }\end{array}$ & Manager & Vanuatu Copra Processing Limited & $\begin{array}{l}\text { VCPL is the second largest oil mill in } \\
\text { Vanuatu and is government owned }\end{array}$ \\
\hline $\begin{array}{l}\text { Thomas } \\
\text { Bangalini }\end{array}$ & $\begin{array}{l}\text { Natural Resources } \\
\text { Sectoral Analyst }\end{array}$ & $\begin{array}{l}\text { Department of Economic and Sectoral } \\
\text { Planning (GoV) }\end{array}$ & \\
\hline Tony Deamer & $\begin{array}{l}\text { Owner/Manager, } \\
\text { mechanic }\end{array}$ & Motor Traders & $\begin{array}{l}\text { Motor Traders is a small scale producer } \\
\text { of coconut biofuel as well as mechnical } \\
\text { services }\end{array}$ \\
\hline Yann Do Quang & Engineer & Unelco & $\begin{array}{l}\text { Yann is the engineer for Tagabé's two } \\
4 \mathrm{MW} \text { diesel generators }\end{array}$ \\
\hline
\end{tabular}


TE WHARE WĀNANGA O TE ŪPOKO O TE IKA A MĀUI

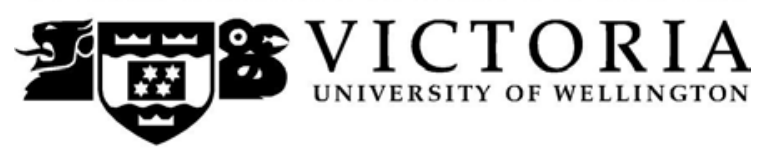

MEMORANDUM

Phone $\quad 0-4-4635676$

Fax $\quad 0-4-4635209$

\begin{tabular}{l|l}
\hline TO & Tim Hewitt \\
\hline COPY TO & Dr Sean Weaver, Supervisor \\
\hline FROM & Dr Allison Kirkman, Convener, Human Ethics Committee \\
\hline
\end{tabular}

\begin{tabular}{l|l}
\hline DATE & 27 October 2007 \\
\hline PAGES & 1 \\
\hline
\end{tabular}

\begin{tabular}{l|l}
\hline SUBJECT & $\begin{array}{l}\text { Ethics Approval: No 15267, Coco-Power: Exploring the } \\
\text { barriers to the use of copra-derived biodiesel in grid } \\
\text { connected electricity generation in Port Vila }\end{array}$ \\
\hline
\end{tabular}

Thank you for your application for ethical approval, which has now been considered by the Standing Committee of the Human Ethics Committee.

Your application has been approved and this approval continues until 29 February 2008. If your data collection is not completed by this date you should apply to the Human Ethics Committee for an extension to this approval. 
Best wishes with the research.

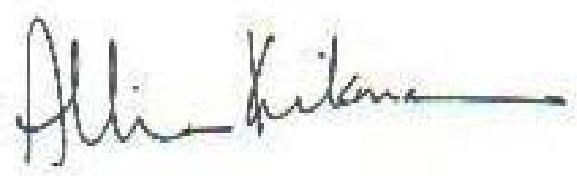

Allison Kirkman

Convener 


\section{APPENDIX 3: PROPOSED INTERVIEW SCHEDULE}

\section{CHAMBER OF COMMERCE}

I will aim for us to have a general discussion of the pros and cons of the commercial opportunities for Vanuatu of copra-based bio-fuel. In particular I will seek opinion on the following issues:

- What are the major barriers to large scale bio-diesel production in Vanuatu?

- Is the Government supportive of pursuing bio-fuel opportunities?

- Is there difficulty in sourcing investment finance for commercial projects in Vanuatu?

\section{COCONUT OIL PROCESSING VANUATU (COPV)}

I will lead a general discussion about the prospect of producing bio-diesel in Vanuatu, as well as seeking a basic description of their business and oil mill.

- What are the major barriers to large scale bio-diesel production in Vanuatu?

- Is the Government supportive of pursuing bio-fuel opportunities?

- Is there difficulty in sourcing investment finance for commercial projects in Vanuatu?

- What is the capacity of the COPV oil mill?

- What is the quality of copra oil produced at COPV?

- How close to capacity has the mill been running? Are there difficulties in sourcing enough copra?

\section{DEPARTMENT OF CUSTOMS \& INTERNAL REVENUE}

I will endeavour to find out the current taxation situation for fossil fuels compared to bio-fuels. 
- Are fuels taxed differently depending on their final use (electricity, transport, stationary, etc)?

- Are biofuels treated differently to fossil fuels?

- How are mixes of bio-fuel and fossil fuel treated?

\section{DEPARTMENT OF SECTOR PLANNING AND ECONOMIC DEVELOPMENT}

I will aim for us to have a general discussion of the pros and cons of the commercial opportunities for Vanuatu of copra-based bio-fuel. In particular I will seek opinion on the following issues:

- What are the major barriers to large scale bio-diesel production in Vanuatu?

- Is the Government supportive of pursuing bio-fuel opportunities?

- Is there difficulty in sourcing investment finance for commercial projects in Vanuatu?

\section{DEPARTMENT OF STATISTICS}

I will be asking the Department of Statistics for various specific datasets:

- Exchange rate history

- Diesel import price history

- Copra Production

- Coconut oil production

- Diesel imports

- Copra price history

- Coconut oil historical prices

- Area of land planted in copra

- Diesel usage for electricity generation 
- Electricity generation from diesel

- Copra's importance in the economy (\% of GDP, \% of exports)

ENERGY UNIT (GOVERNMENT OF VANUATU)

I will lead a broad discussion of the project. In particular I will raise the aspect of potential revenue from a clean development mechanism transaction and whether this would improve the viability of a bio-fuel project? I will ask the Energy Unit what work streams they currently have in place regarding bio-fuels as well as what they have done in the past.

\section{FUEL RETAIL COMPANIES}

I will ask the fuel companies what their thoughts on bio-fuels in Vanuatu are, as well as more specific questions that relate to their ability to integrate bio-fuels into the market:

- What do they think the main barriers to implementing a large scale bio-fuels project in Vanuatu is?

- Would an extra fuel type cause practical or logistical problems for distribution, storage, etc?

- If blending were to occur, where do they think it should be done (bio-fuel producer, port/wharf, other)?

- Do they think that there could be strong support for bio-fuel for transport?

- Do they have preferences on what sort of bio-fuel would be appropriate (diesel and vegetable oil blended, or transesterified bio-diesel)?

- Have they heard of the clean development mechanism?

MINISTRY OF TRADE, COMMERCE AND INDUSTRY

I will aim for us to have a general discussion of the pros and cons of the commercial opportunities for Vanuatu of copra-based bio-fuel. In particular I will seek opinion on the following issues: 
- What are the major barriers to large scale bio-diesel production in Vanuatu?

- Is the Government supportive of pursuing bio-fuel opportunities?

- Is there difficulty in sourcing investment finance for commercial projects in Vanuatu?

TONY DEAMER - MOTOR TRADERS

I will be asking Tony about what process he uses to produce bio-diesel, and also talk in general about his experience producing it.

- What are the main barriers likely to be for larger scale production of bio-fuel?

- What is his supply arrangement for copra?

\section{UNELCO}

I will have a general discussion with Unelco about the potential for a bio-fuel project, as well as asking for a description of their business and generation plant:

- What are their supply arrangements for diesel from oil companies?

- How high a blend of bio-diesel do they think could be safely used in their electricity generation plant at Vila?

- What type (number, capacity, make) of generators do they have in Vila?

- Would they be prepared to have somebody invest in their generation system so that it could run solely on bio-fuel?

- What are the main barriers to Unelco running their Vila plant on bio-fuel?

- Is Unelco aware of the clean development mechanism under the Kyoto Protocol?

VANUATU COMMODITIES MARKETING BOARD (VCMB)

I will broadly open discussions on the market situation of copra in Vanuatu. Some specific questions would be:

- How is the price determined? 
- What is the typical yield of copra per year?

- How consistent is yield throughout the year (i.e. any seasonality)?

- What are the export markets?

VANUATU COPRA PROCESSING LTD (VCPL)

This interview would likely run in combination with the VCMB interview as VCPL is a subsidiary of VCMB. In addition to the VCMB interview questions I would also ask for a general description of the VCPL plant:

- What is their oil production capacity?

- What is their target market (export or domestic)?

- Do they have any future plans with bio-fuel?

- How much copra do they process?

- Do they have difficulty sourcing sufficient copra?

VANUATU RENEWABLE ENERGY \& POWER ASSOCIATION

(VANREPA)

I will be raising technical energy questions that come up whilst in Vanuatu. An example could be "what is the electricity generation capacity required for a village of fifty families?" I may also discuss the possibility of other emission reduction projects. 
The details of the interviews have been omitted from this publication to protect the confidentiality of the interviewees. 